\title{
HILGARDIA
}

A Journal of Agricultural Science Publisbed by the California Agricultural Experiment Station

\section{FACTORS AFFECTING THE ASEPTIC CULTURE OF LOVELL PEACH SEEDLINGS}

DALE E. KESTER

UNIVERSITY OF CALIFORNIA - BERKELEY, CALIFORNIA 
THIS PAPER PRESENTS investigation of factors affecting the germination and growth of Lovell peach embryos. Presence of the cotyledons, length of after-ripening, sucrose, light, and a number of accessory substances are considered. The technique used consisted of aseptic stratification of Lovell peach seeds followed by the aseptic culture of the embryos on nutrient agar.

The studies showed that reduction in the amount of cotyledons reduced over-all growth, and their complete removal prevented germination. With limiting amounts of the cotyledons the additional specific effect of inhibiting internode elongation appeared. Root length was not reduced until about 90 per cent of the cotyledons were removed. Injury resulted in initial stimulation to shoot growth.

Addition of sucrose to the medium tended to be inhibiting when large amounts of cotyledons were present but became stimulating as they were reduced, and with ecotyledonized embryos allowed germination, though growth was maintained for only 10 to 14 days, a rosettelike shoot developed, and root tips became blackened. Increasing the length of after-ripening tended to increase growth. In darkness, internode inhibition was not present, but inhibition in root elongation was evident and the cotyledons did not overcome root-tip blackening.

The function of the cotyledons seemed to be twofold: (1) to produce growth of shoots, leaves, and roots; and (2) to provide a stimulus for growth after germination had started. As little as $1 / 16$ of the cotyledons could carry out both functions. The effect of the cotyledons could not be replaced by any of the accessory substances tested, though some of them had a slight stimulating effect on shoot or root growth or both.

A similarity between growth from ecotyledonized embryos (embryos with cotyledons removed), growth of excised immature embryos, and growth from non-after-ripened embryos is pointed out and the significance discussed. 


\section{II $\mathrm{C}$ A Journal of Agricultural Science Published by \\ the California Agricultural Experiment Station \\ VoL. 22 \\ SEPTEMBER, 1953 \\ FACTORS AFFECTING THE ASEPTIC CULTURE OF LOVELL PEACH SEEDLINGS ${ }^{1}$}

No. 9

\section{DALE E. KESTER}

EARLY RIPENING VARIETIES of peaches, plums, and cherries consistently produce nonviable embryos. This has been known to horticulturists for many years. The occurrence of the phenomenon is a serious obstacle in the production of early-ripening hybrids in fruit-breeding programs. Germination of many of these varieties has been induced by the use of embryo culture. The present investigation was an attempt to determine some of the growth requirements of peach embryos in the hope that such knowledge might make it possible to extend the scope of methods of embryo culture now in use. The purposes may be stated as follows: to determine the effect of the removal of cotyledons on the growth of seedlings from mature, germinable Lovell peach embryos and to determine the effect of various factors on the growth of ecotyledonized seedlings.

No term exists to designate that part of the embryo made up of the hypocotyl, plumule, and radicle exclusive of the cotyledons. In this paper the term "ecotyledonized embryo" is used to designate an embryo mechanically separated from its cotyledons.

The physiological basis of nonviability of early-ripening stone fruit varieties is related to the degree of embryo development at the time the fruit is ripe (Tukey, 1937). Growth of the peach fruit has been separated into two different growth stages, one immediately after fertilization of the ovule, the other (occurring later) terminating in fruit ripening. In between occurs a period of retardation (Baker and Davis, 1951). The beginning of the final growth stage of the fruit (mesocarp) determines the duration of this period of retardation which, in turn, is correlated to the time of ripening. Rapid embryo enlargement begins near the end of the first growth stage, and the embryo grows to full size during the period of retardation. In the case of early-ripening varieties the final growth stage of the fruit may take place while the embryo is still developing (Tukey, 1933b). Accumulation of reserve substances by the embryo takes place largely after completion of its morphological development (Lee and Tukey, 1942). Consequently, in the case of early-ripening varieties, the embryo may not have developed sufficiently for germination by the time the fruit is ripe.

\footnotetext{
${ }^{1}$ Received for publication October 2, 1952.

${ }^{2}$ Lecturer in Pomology and Assistant Pomologist in the Experiment Station, Davis.
} 
That embryos of early-ripening varieties are potentially viable was shown by Tukey $(1933 a)$. He used embryo culture on an extensive scale with cherries, peaches, plums, apples, and pears (Tukey, 1934). Many of the earliest ripening varieties of peaches, however, have not responded to the method (Davidson, 1933; Lammerts, 1942).

Germination of immature embryos by embryo culture was investigated by Hannig (1904) and Dieterich (1924). Use of the technique in production of normally nonviable hybrid seed was first reported by Jorgensen (1928) and Laibach (1929). Studies of LaRue (1936), Loo and Wang (1943), Merry (1942), and Brink, Cooper, and Ausherman (1944) showed the existence of a minimum embryo size below which germination could not take place. Furthermore the embryo separated from the fruit omitted the later stages of development and grew directly into a seedling. Tukey (1938) found that the morphological appearance of the seedling was characteristic of the relative degree of development at the time the embryo was excised. With Datura and Hordeum, substances such as coconut milk (van Overbeek, Conklin, and Blakeslee, 1942), unautoclaved malt extract (Blakeslee and Satina, 1944), casein hydrolysate (Sanders and Burkholder, 1948), and tomato juice (Kent and Brink, 1947) have been used successfully to maintain embryo development in vitro. Other species investigated have not responded to such materials (Hall, 1948; Lofland, 1950; Smith, 1944).

Another approach to the problem is to determine the nutritional requirements and conditions to germinate immature embryos directly. A group of growth substances added to the culture medium was shown to stimulate growth of excised Datura embryos (van Overbeek, Conklin, and Blakeslee, 1942). Of these pantothenic acid and succinic acid were later shown to be the effective members (Bonner and Bonner, 1948).

Investigations have been made concerning growth of mature embryos separated from their storage organs, cotyledons and endosperm. Sachs (1862), Van Tiegham (1873), and Haberlandt (1877), finding that such embryos of a number of species were unable to develop, concluded that these organs were necessary to provide not only a growth stimulus but also substances needed for development of seedling parts (Stingl, 1907). Blociszewsky (1876), on the other hand, found cotyledons necessary only to give vigor.

Nutrients shown to be necessary or stimulatory to pea embryos separated from their cotyledons include mineral salts, sugars, members of the vitamin-B complex, and ascorbic acid (Kögl and Haagen-Smit, 1936 ; Bonner and Axtman, 1937 ; Bonner, 1938; Rytz, 1939; Von Hausen, 1948). Auxin has been shown to be present in seeds (Berger and Avery, 1944; Avery, Berger, and Shalucha, 1942 ; Stewart, 1939) and probably plays an important part in germination and growth of seedlings. The necessity for specific substances for organ formation, in addition to auxin, has been suggested (Cooper, 1938 ; Went, 1938).

\section{PROCEDURE}

The method of aseptic stratification and embryo culture developed by Gilmore (1950) was used. In brief, the procedure consisted of 5 minutes' sterilization of dry Lovell peach seeds in 1:2,000 Merthiolate ${ }^{3}$ solution of 50 per

${ }^{3}$ Eli Lilly and Co., Indianapolis, Indiana. 
cent ethyl alcohol followed by 5 minutes' washing in sterile tap water. The seeds were after-ripened in the sterile water for at least 90 days at $36^{\circ} \mathrm{F}$. Then seed coats were removed and the embryos planted on 20 milliliters of 0.7 per cent agar ${ }^{4}$ medium in $25 \times 200 \mathrm{~mm}$ test tubes. The basic medium was a modified Hoagland's solution, including minor elements (Hoagland and Arnon, 1938). Sucrose was supplied as commercial cane sugar.

The culture room was in a basement with light provided by $4,500^{\circ} \mathrm{K}$ daylight fluorescent lights set for a 14-hour day. Duration of most experiments was 18 to 20 days, and 10 cultures were used for each treatment.

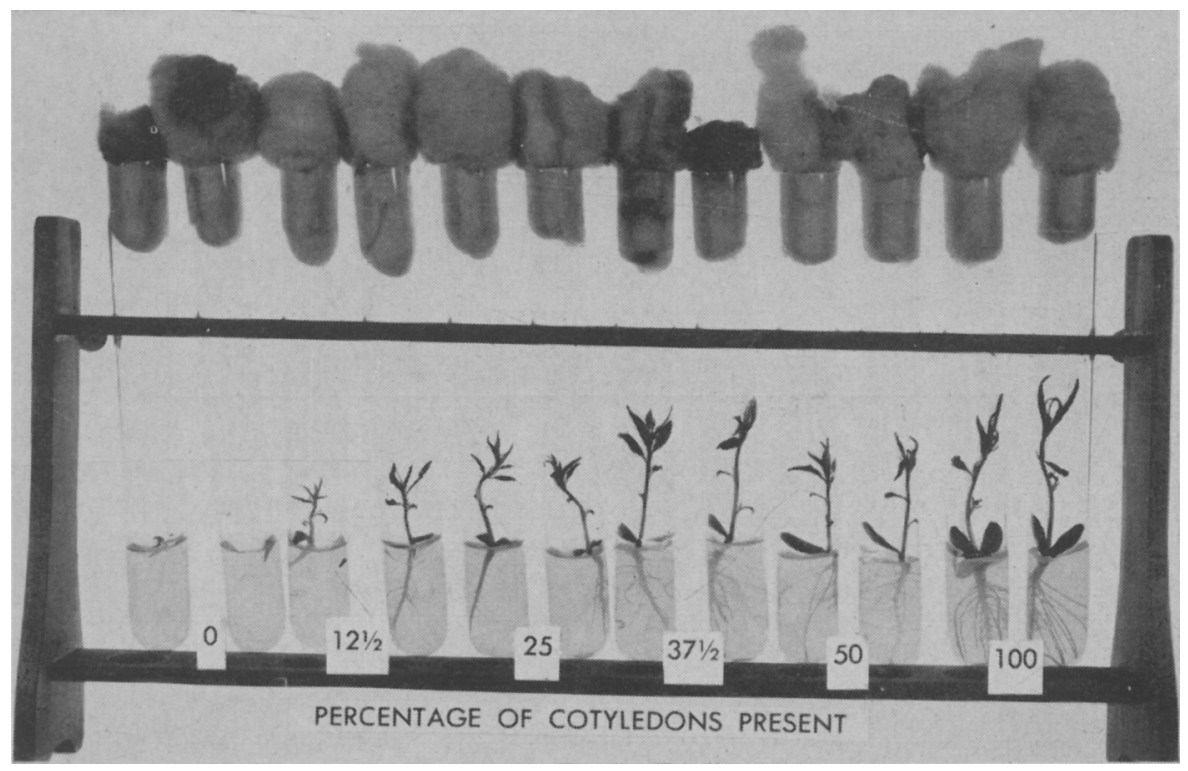

Fig. 1. Lovell peach seedlings from embryos with different amounts of cotyledons attached, after 10 days' growth on the basic medium. Stimulation brought about by cutting through the cotyledons is shown in the seedlings from the $371 / 2$ per cent embryos in contrast to the seedlings from the 50 per cent embryos, where no such cut was made.

\section{FACTORS AFFECTING THE GROWTH OF SEEDLINGS WITH ATTACHED COTYLEDONS}

\section{The Effect of Gradual Cotyledon Reduction on Seedling Growth}

The effect of gradual cotyledon reduction on seedling growth was studied with embryos growing on various media. The results of one of these experiments in which the culture medium was a modified Hoagland's solution will be presented. The amounts of reduction are given in table 1 . Different reductions are referred to as the percentage of cotyledons present.

Ecotyledonized embryos failed to germinate, whereas embryos which had some part of the cotyledons attached germinated and produced seedlings that were essentially normal (fig. 1). Over-all growth at the end of the culture

${ }^{4}$ American Agar \& C. Co., San Diego, Calif. Washed by daily changes of distilled water for a week. 
period (fig. 2) showed a direct relation between the weight of the seedling and the original weight of the embryo.

Changes in dry weight taking place during the culture period are given in table 2. Although the total amount of material from the cotyledons used depended on the initial amount present, loss in each case was approximately 80 per cent. Apparently this was the amount available to the seedling. A

TABLE 1

DRY WEIGHT OF LOVELL PEACH EMBRYOS WITH DIFFERENT PROPORTIONS OF THE COTYLEDONS REMAINING

\begin{tabular}{|c|c|c|}
\hline $\begin{array}{l}\text { Amount of cotyledons } \\
\text { remaining }\end{array}$ & $\underset{(\mathbf{m g})}{\text { Dry weight }}$ & $\begin{array}{l}\text { Per cent } \\
\text { of total }\end{array}$ \\
\hline 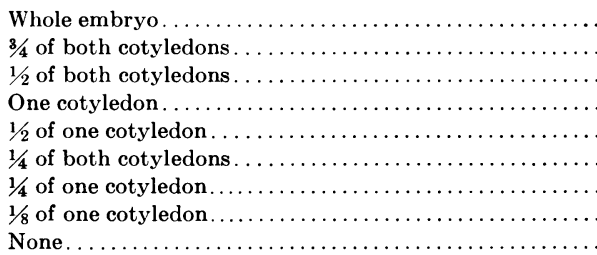 & $\begin{array}{r}350 \\
299 \\
182 \\
175 \\
84 \\
68 \\
31 \\
19 \\
2.1\end{array}$ & $\begin{array}{r}100 \\
86 \\
52 \\
50 \\
24 \\
19 \\
8.9 \\
5.4 \\
0.6\end{array}$ \\
\hline
\end{tabular}

TABLE 2

EFFECT OF INITIAL AMOUNTS OF COTYLEDONS ON CHANGES IN DRY WEIGHT DURING GERMINATION OF LOVELL PEACH EMBRYOS

Cultures grown 23 days on agar medium with added modified Hoagland's solution

\begin{tabular}{|c|c|c|c|c|c|c|c|}
\hline \multirow{2}{*}{$\begin{array}{l}\text { Per cent } \\
\text { of } \\
\text { cotyledons } \\
\text { remaining }\end{array}$} & \multirow{2}{*}{$\begin{array}{c}\text { Dry weight } \\
\text { of } \\
\text { seedling, } \\
\text { mg }\end{array}$} & \multicolumn{3}{|c|}{ Dry weight of cotyledons, mg } & \multirow{2}{*}{$\begin{array}{c}\text { Per cent } \\
\text { reduction in } \\
\text { cotyledon } \\
\text { weight }\end{array}$} & \multirow{2}{*}{$\begin{array}{c}\text { Net loss, } \\
\text { mg }\end{array}$} & \multirow{2}{*}{$\begin{array}{l}\text { Per cent } \\
\text { net loss }\end{array}$} \\
\hline & & Initial & Final & Reduction & & & \\
\hline 100 & 226 & 350 & 74 & 276 & 79 & 50 & 14 \\
\hline 86 & 209 & 299 & 73 & 226 & 76 & 17 & 6 \\
\hline 52 & 80 & 182 & 30 & 152 & 84 & 72 & 40 \\
\hline 50 & 124 & 175 & 38 & 137 & 78 & 13 & 7 \\
\hline 24 & 50.2 & 84.1 & 16.5 & 67.6 & 80 & 17 & 21 \\
\hline 19 & 33.8 & 68.0 & 11.0 & 57.0 & 84 & 23 & 34 \\
\hline 8.9 & 19.2 & 31.1 & 6.5 & 24.6 & 79 & 5.4 & 17 \\
\hline 5.4 & 11.5 & 18.8 & 4.1 & 14.7 & 78 & 3.2 & 17 \\
\hline
\end{tabular}

net loss in weight occurred during the culture period, tending to decrease with a decrease in initial weight (although this was not true on a percentage basis).

It has been noticed in numerous instances that cutting to reduce the cotyledons has an influence on growth of the resulting seedling. This influence was particularly evident as an initial stimulation to elongation of the shoot. Figure 1 shows this effect on seedlings from $371 / 2$ per cent embryos as compared to 50 per cent embryos. In another test, seedlings from 86 per cent embryos (where the tips were removed) had greater fresh weight than seedlings from the whole embryos, although shoot length was nearly the same. Figure 3 shows the changes in shoot length throughout the culture 
Fig. 2, at right. The relation of the initial amount of cotyledons (percentage of total dry weight) to the final weight of Lovell peach seedlings grown 23 days on the basic medium.

Fig. 3, below. Comparison of daily changes in shoot length of Lovell peach seedlings from 52 per cent embryos and 50 per cent embryos. This shows the initial rapid elongation of the shoot of the seedlings from the 52 per cent embryos, followed by a reduced rate of elongation, as compared with seedlings from the 50 per cent embryos.

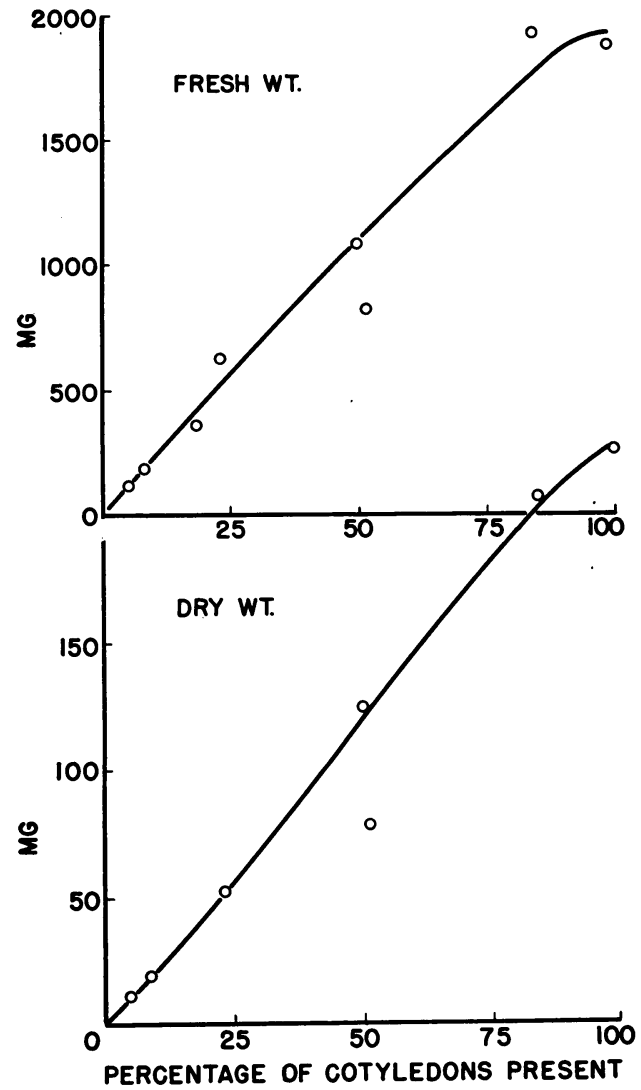

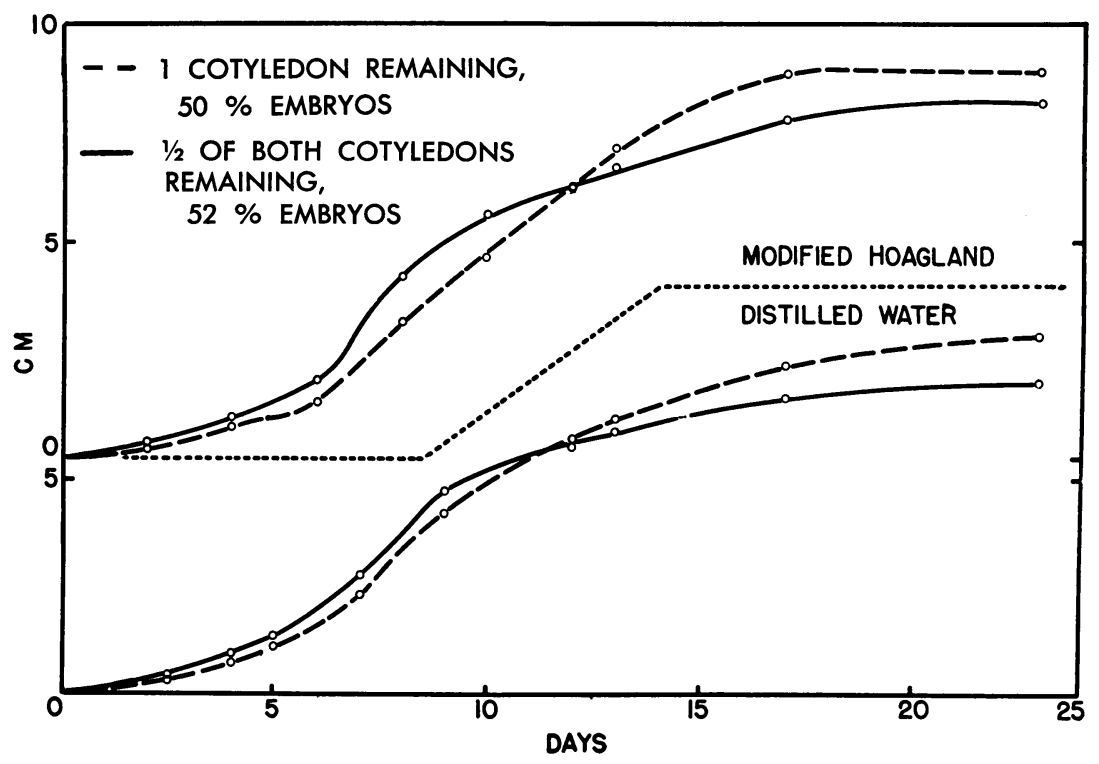


period on two different media of seedlings from 50 per cent embryos (one cotyledon removed, no cut made) and 52 per cent embryos (both cotyledons cut). The 52 per cent embryos showed greater shoot elongation initially, but by the twelfth day the 50 per cent embryos had surpassed them.

In dry-weight changes (table 2) more material was removed from the cotyledons of the 52 per cent embryos than from the 50 per cent embryos. However, in the former the seedlings at the end of the culture period were smaller, and net loss was greater, indicating that the material was not used so efficiently in growth. The per cent net loss tended to be large in all the

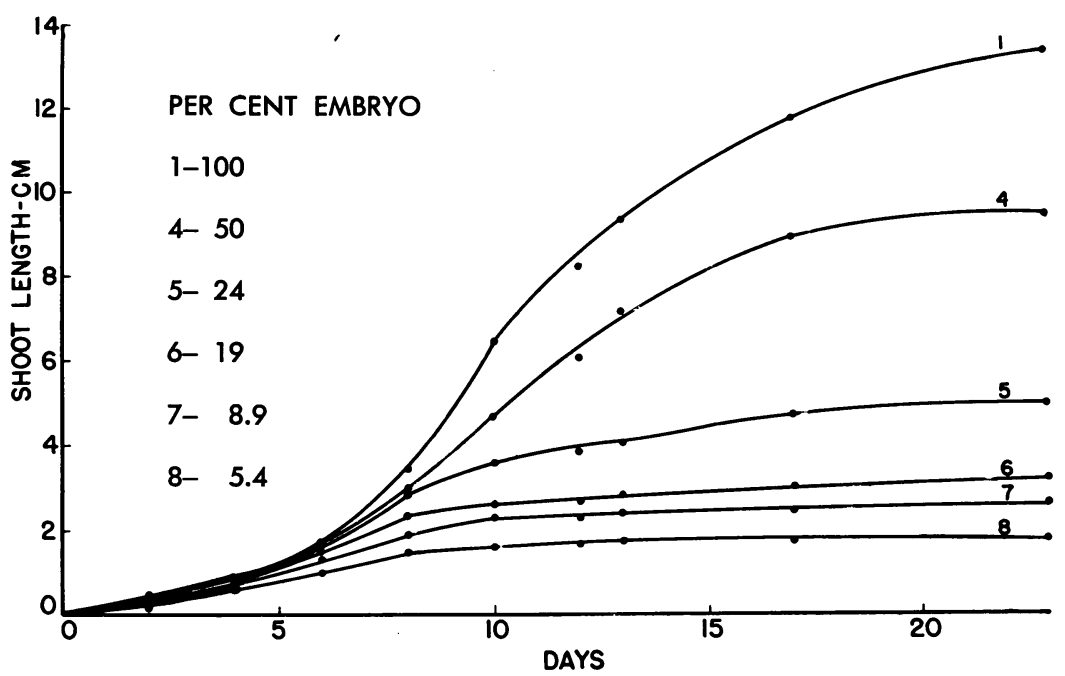

Fig. 4. The shoot growth of seedlings from embryos with different percentages of cotyledons present, growing on the basic medium (modified Hoagland's solution).

seedlings where a small per cent of cotyledons remained; in each case a large amount of cutting took place.

Shoot Length. Changes in growth of the shoot throughout the culture period are shown in figures 4 and 5. Particularly evident is the influence of the cotyledons on the growth rate of the shoot. The magnitude of this growth rate was in direct proportion to the percentage of cotyledons present, as was also final size. Furthermore the peak in growth rate was reached later as the amount of cotyledons increased.

Table 3 indicates that the reduction in seedling size with reduced cotyledons was produced by both number and length of internodes. However, as the amount of cotyledons approached a minimum, difference in size was shown by reduction of internodal length. This tendency was observed in the rosettelike growth exhibited by such seedlings.

Root Growth. Two effects upon root growth were evident, one on the elongation of the primary root and the other on the amount of lateral roots. A typical root system was one in which a great number of lateral roots was produced in the first 5 to 6 centimeters, the number and length of laterals decreasing toward the tip. Appearance of the root systems of seedlings on 


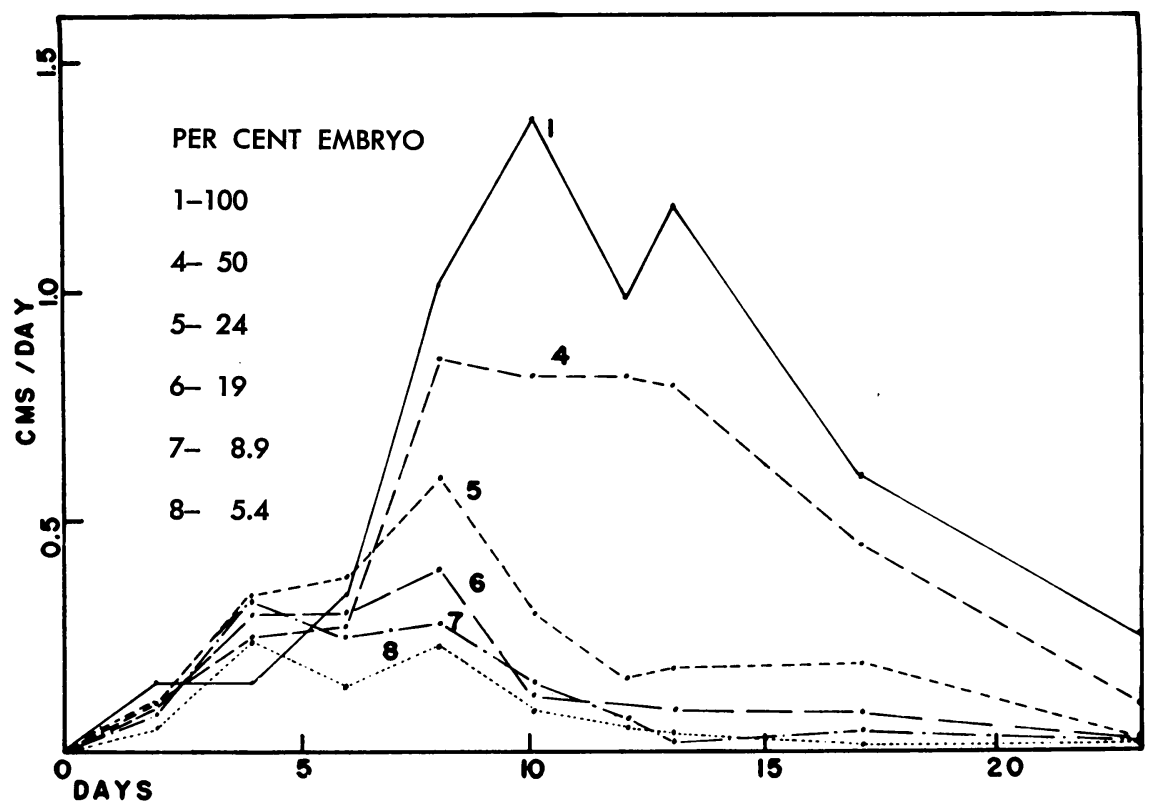

Fig. 5. The growth rate of shoots from seedlings from embryos with different percentages of cotyledons present, growing on the basic medium (modified Hoagland's solution).

TABLE 3

EFFECT OF INITIAL AMOUNTS OF COTYLEDONS ON SHOOT LENGTHS, NUMBER

OF INTERNODES, AND LENGTH OF

INTERNODES OF LOVELL PEACH SEEDLINGS

Grown 23 days on agar medium with added modified

Hoagland's solution

\begin{tabular}{c|c|c|c}
\hline $\begin{array}{c}\text { Per cent } \\
\text { of cotyledons } \\
\text { remaining }\end{array}$ & $\begin{array}{c}\text { Length } \\
c m\end{array}$ & $\begin{array}{c}\text { Number } \\
\text { of } \\
\text { internodes }\end{array}$ & $\begin{array}{c}\text { Length } \\
\text { of internodes } \\
c m\end{array}$ \\
\cline { 1 - 2 } 100 & 13.3 & 16.9 & 0.79 \\
86 & 13.0 & 17.8 & .73 \\
52 & 8.1 & 14.6 & .56 \\
50 & 9.5 & 15.4 & .62 \\
24 & 5.0 & 12.3 & .40 \\
19 & 3.2 & 10.9 & .30 \\
8.9 & 2.6 & 8.0 & .33 \\
5.4 & 1.8 & 8.6 & 0.21 \\
\hline
\end{tabular}

the modified Hoagland's solution as well as on a "distilled water", medium is shown in figure 6.

Reduction in the initial amount of cotyledons was more closely associated with lateral-root production than with length of the primary root. Primaryroot length on the modified Hoagland's solution was not materially decreased until 90 per cent of the cotyledons was removed. With the distilled-water

${ }^{5}$ Analysis showed that the agar supplied some minerals, particularly sodium, chlorine, calcium, and magnesium. 
DISTILLED WATER:
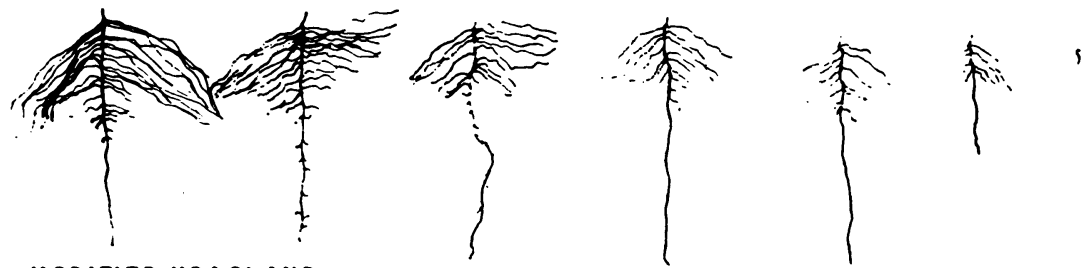

MODIFIED HOA GLAND:
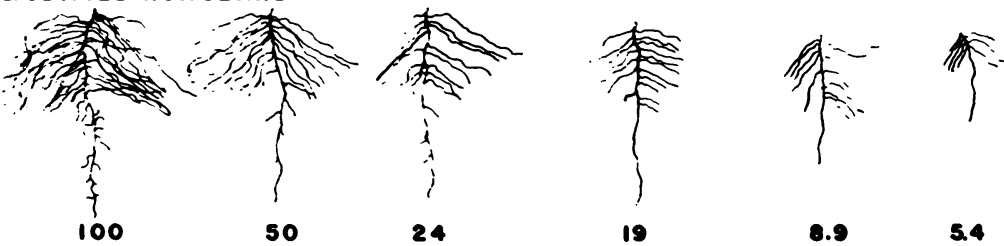

19

8.9

5.40

PERCENTAGE OF COTYLEDONS PREBENT

Fig. 6. The relation of initial amount of cotyledons (percentage of total dry weight) to the root systems of Lovell peach seedlings grown 23 days on the basic medium and on distilled-water medium.

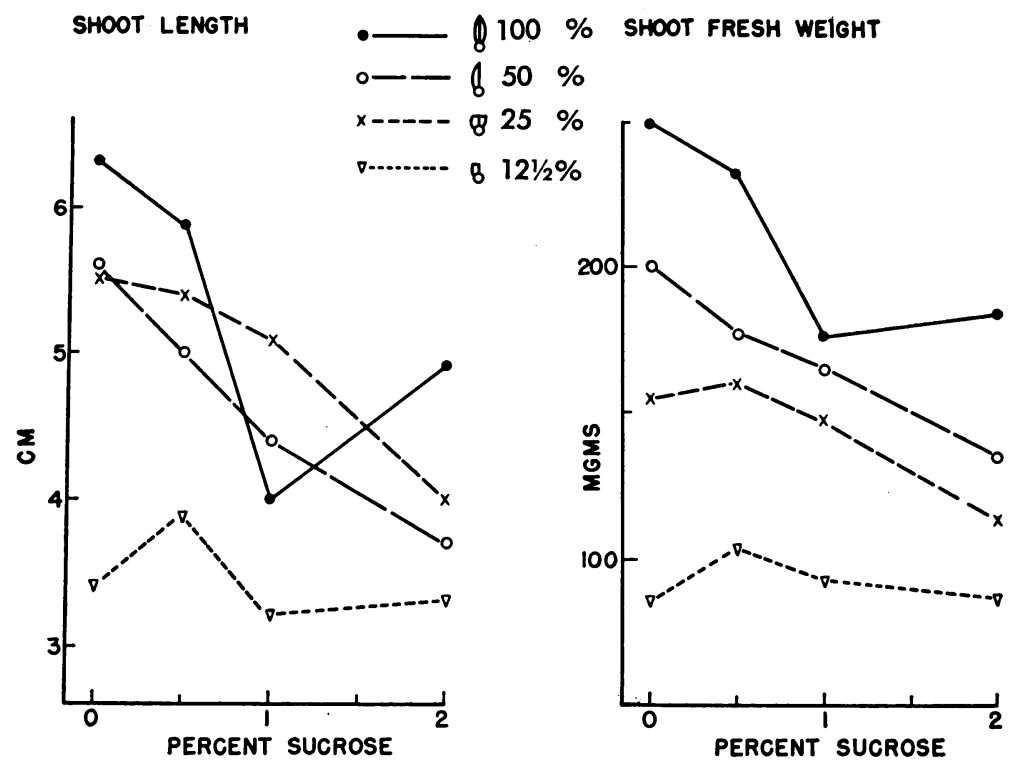

Fig. 7. The effect of sucrose on shoot growth of Lovell peach seedlings from embryos with different percentages of cotyledons attached, after 3 weeks' growth in aseptic culture.

medium, reduction did not occur until 95 per cent of the cotyledons was removed. This difference in the two media has been noted in several instances.

The Relation of Sucrose to the Amount of the Cotyledons Present

Preliminary to the experiment just reported, a series of cotyledon-reduction experiments was conducted, in which different sucrose concentrations were 
investigated in relation to the amount of cotyledons present. Data will be presented from five of these experiments carried out over a period of five weeks, including two using the basic medium and one each with 0.5 per cent, 1 per cent, and 2 per cent sucrose added.

Sucrose was inhibiting to shoot growth when one fourth or more of the cotyledons was present but had little or no effect when they were reduced below that amount (fig. 7). The effect was shown by both shoot length and shoot fresh weight. A close correlation existed between length and fresh weight of the shoot in each medium. Fresh weight increased with an increase
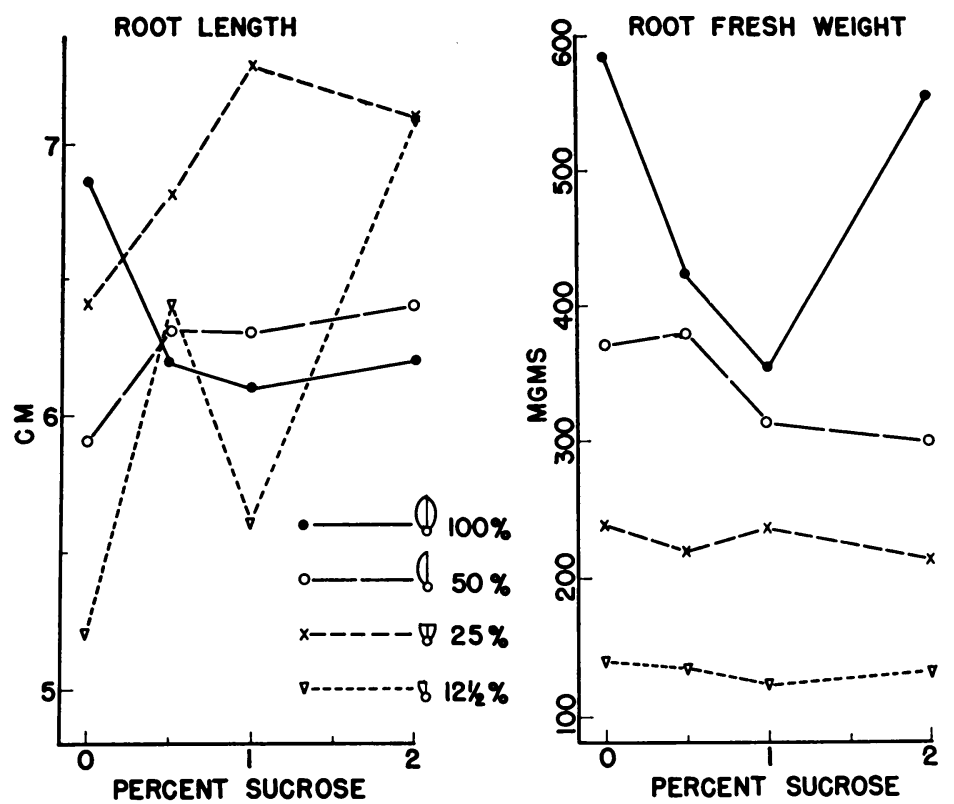

Fig. 8. The effect of sucrose on root growth of Lovell peach seedlings from embryos with different percentages of cotyledons attached, after 3 weeks' growth in aseptic culture.

in the amount of cotyledons on all media, but shoot length was consistently greater with one fourth than with one half of the cotyledons present. Apparently this represents another case of stimulus due to cotyledon injury, expressed in length of shoot but not in over-all increase in growth.

Total root growth, as indicated by fresh weight, showed a tendency similar to that of the shoot; with large amounts of cotyledons, sucrose inhibited it, the effect disappearing as the cotyledons were reduced (fig. 8). Seedlings from 100 per cent embryos growing on 2 per cent sucrose were an exception where fresh weight was markedly increased over that on 0.5 and 1 per cent sucrose. Length of the primary root of the 100 per cent embryos was inhibited by sucrose, but the effect changed to stimulation as the cotyledons were reduced.

Comparison of the distribution of weight between the water and drymatter content showed that reduction in water content rather than reduc- 
tion in dry matter was associated with increasing sucrose concentration. Calculated osmotic pressures of the modified Hoagland's solution plus 0.0, $0.5,1.0$, and 2.0 per cent sucrose are approximately $0.6,1.0,1.3$, and 2.1, respectively. The increase in osmotic pressure of the solution may have been effective in reducing the water uptake, although this cannot be the only effect of sucrose. Final dry weight of the entire seedling plus the cotyledons increased in direct proportion to the concentration of sucrose in the external

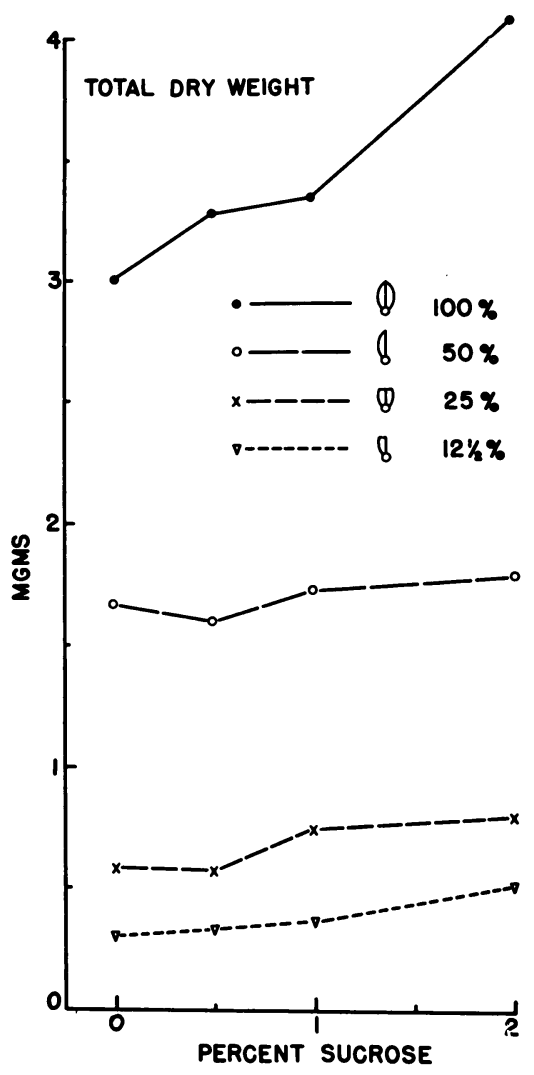

Fig. 9. Effect of sucrose on the total dry weight (including cotyledons) of Lovell peach seedlings from embryos with different percentages of cotyledons attached, after 3 weeks' growth in aseptic culture.

medium (fig. 9). Sucrose was either absorbed by the cotyledons or utilized by the seedling in place of material from the cotyledons. With reduction of the cotyledons, sucrose apparently became more important as a nutrient.

In these experiments on seedlings with reduced cotyledons, response to sucrose was shown more by elongation of the primary root than by elongation of the shoot. Several later experiments showed that the response of the shoot to sucrose changed with the available light conditions. Using a constant amount of the cotyledons (approximately 1/8) sucrose concentration was varied in several experiments. Cultures of one were grown on the laboratory table with daylight and overhead lights. A second was carried out under continuous $4,500^{\circ} \mathrm{K}$ fluorescent lights. Light intensity was not measured but was probably $400-500$ f.c. A third was carried out in an 
enclosed cabinet with a battery of fluorescent lights set for a 14-hour day. Light intensity again was not measured; it was less than the continuous fluorescent but probably more than that of the first. Results of the three experiments are combined in figure 10.
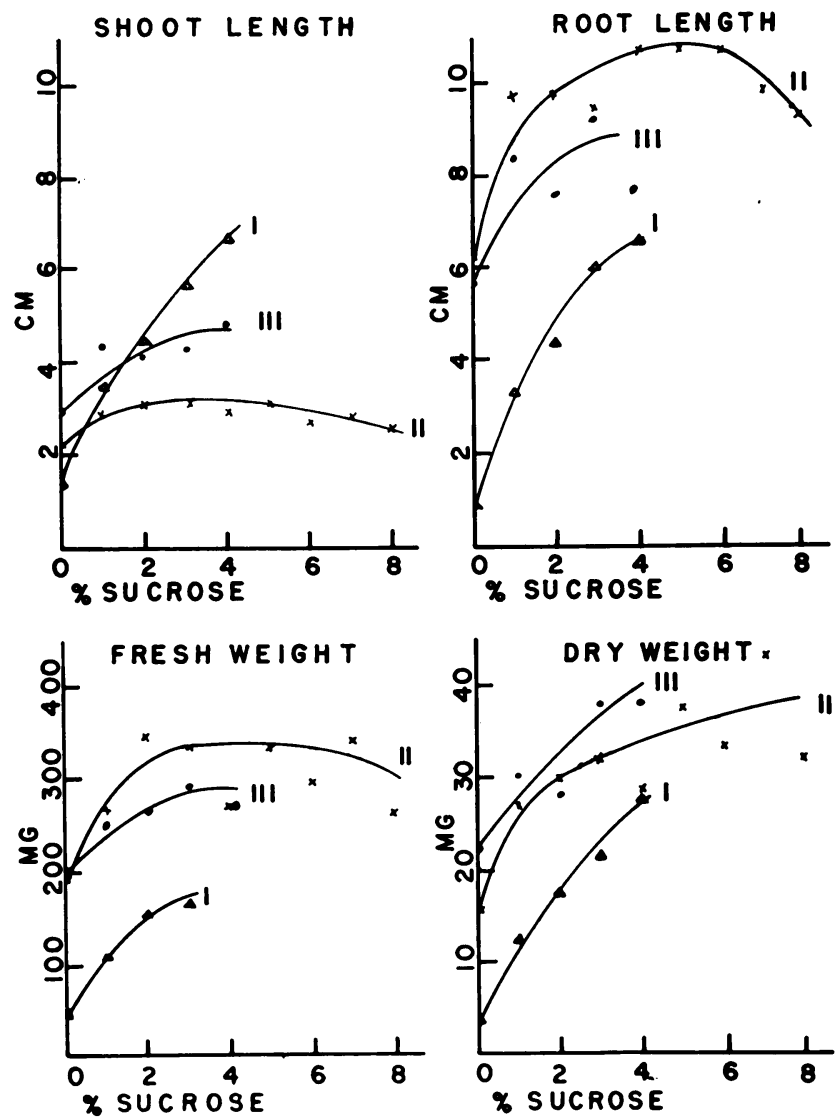

Fig. 10. Comparison of response by Lovell peach seedlings from embryos with $121 / 2$ per cent of cotyledons attached, to change in sucrose concentration as affected by light conditions. I, Ordinary room light (low intensity) ; II, continuous $4,500^{\circ} \mathrm{K}$ fluorescent lights (high intensity); III, $4,500^{\circ} \mathrm{K}$ fluorescent lights, 14-hour day (intermediate intensity).

Shoot length was increased by sucrose, but only at the lowest light intensity was it increased in proportion to change in concentration. With the fluorescent lights of higher intensity, response was less marked, and with the continuous light there was gradual inhibition. Root length, on the other hand, responded to sucrose under all three conditions with an apparent maximum at 4 to 6 per cent. Fresh weight also increased but, with continuous fluorescent light, not above 2 per cent. Dry weight increased under each condition throughout the entire range of concentration. 


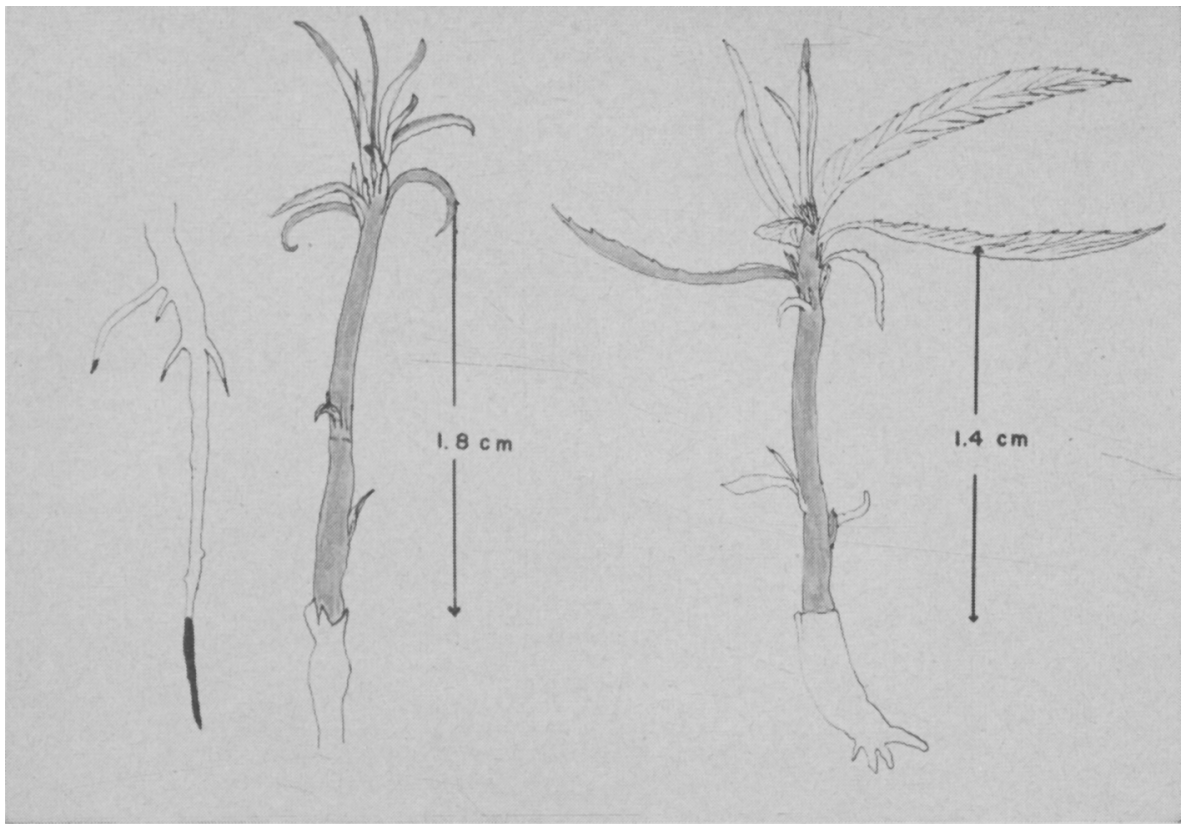

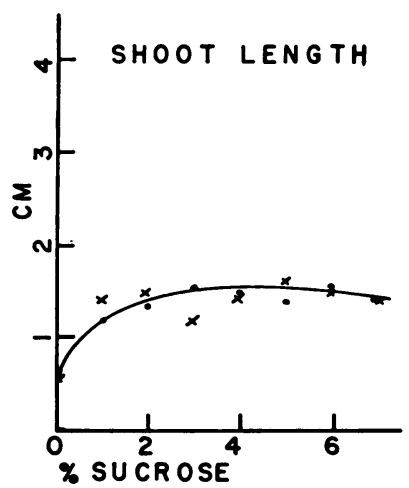
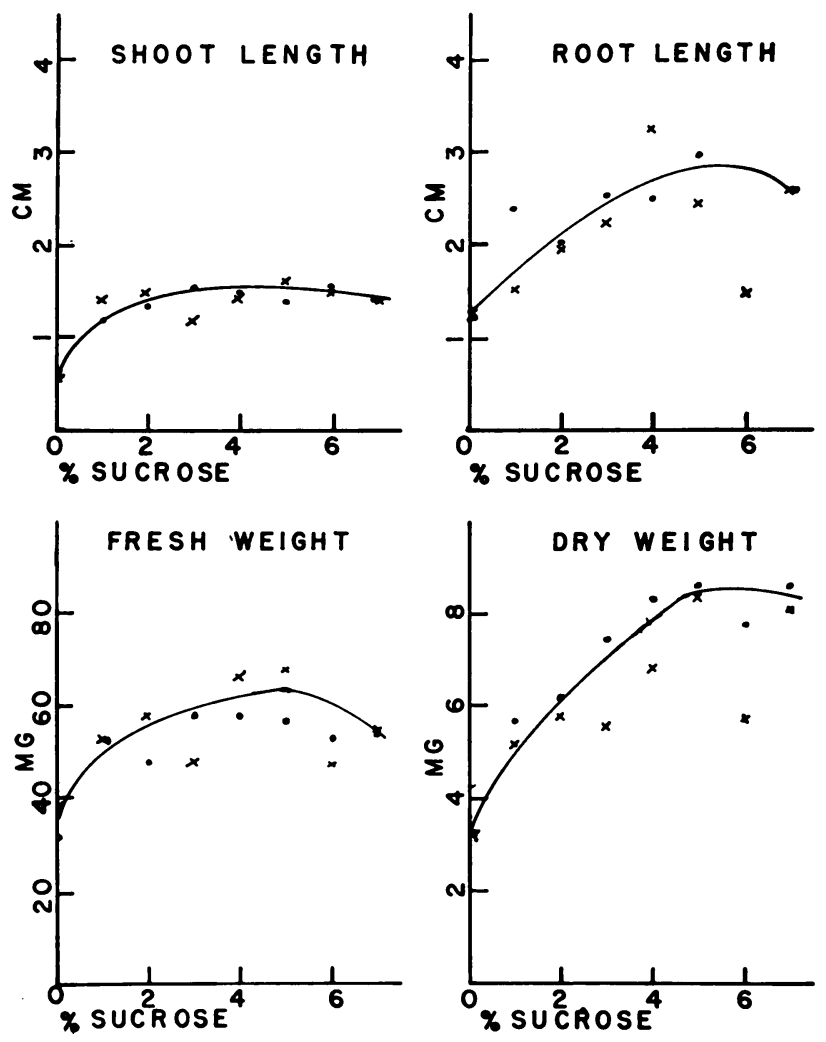

Fig. 11, above. Two typical ecotyledonized seedlings of Lovell peach after 3 weeks' growth in light in a basic medium with added inorganic salts and 4 per cent sucrose. The seedling on the left occurred most often. Note the rosettelike shoot and the blackened root tips. The seedling on the right shows a reduced root system and expanded leaves, which were often chlorotic.
Fig. 12, at left. The effect of sucrose concentration on growth of Lovell peach seedlings from ecotyledonized embryos. The cultures were grown 19 days. $\mathrm{x}$ and $\bullet$ refer to duplicate experiments. 


\section{FACTORS AFFECTING THE GROWTH OF ECOTYLEDONIZED LOVELL PEACH SEEDLINGS}

Ecotyledonized embryos failed to germinate on the basic medium. With the addition of sucrose, germination did take place, but the resulting seedling grew for only 10 to 14 days. The characteristic appearance, which could not be improved by transferring to a fresh medium, is shown in figure 11 . Morphology of the shoot was characterized by a failure of internode elonga-

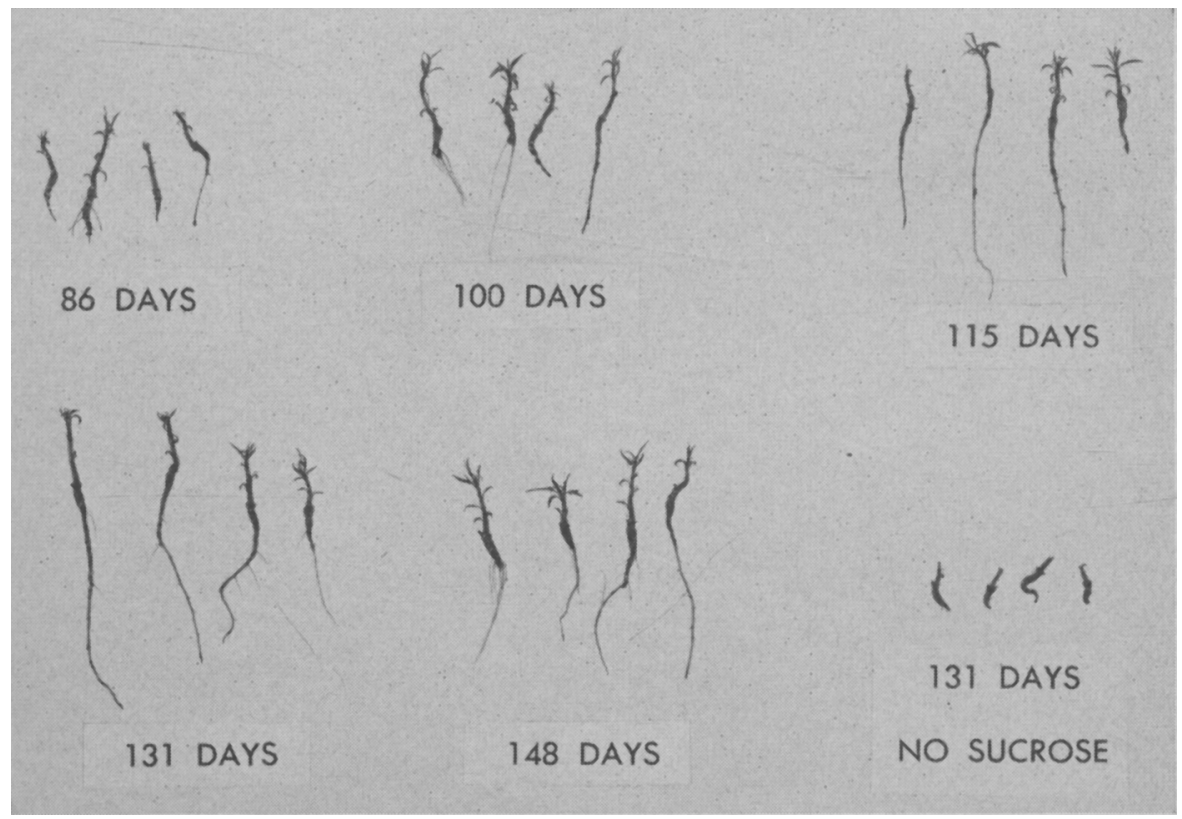

Fig. 13. The effect of length of after-ripening of seeds on ecotyledonized Lovell peach seedlings grown 19 days on an agar medium with added inorganic salts and 4 per cent sucrose.

tion, resulting in a rosettelike structure made up of stipules and small unexpanded leaves. Occasionally leaves would expand normally but be small and generally chlorotic, the latter often associated with a particularly restricted root system.

Radicle elongation ceased after about 10 days, the root tips turning black or brown. Discoloration usually began at the tip of the laterals from the older parts of the root. Few laterals were present, although regular swellings could be observed along the primary root.

\section{Sucrose Concentration}

The response to increase in sucrose concentration was shown mostly by root length and weight (fig. 12). The optimum appeared to be between 4 and 5 per cent. Shoot length was increased by the presence of sucrose but showed little response to a change in concentration. The latter response is similar to that where $1 / 8$ cotyledon remained (discussed in the previous section). 


\section{After-Ripening}

Lengthening the period of seed after-ripening beyond the usual 90 days increased growth of ecotyledonized seedlings. This increase in seedling size, shown in figure 13, was expressed mostly by growth of the root and to a lesser extent by increase in shoot length. Seeds used for this particular ex-
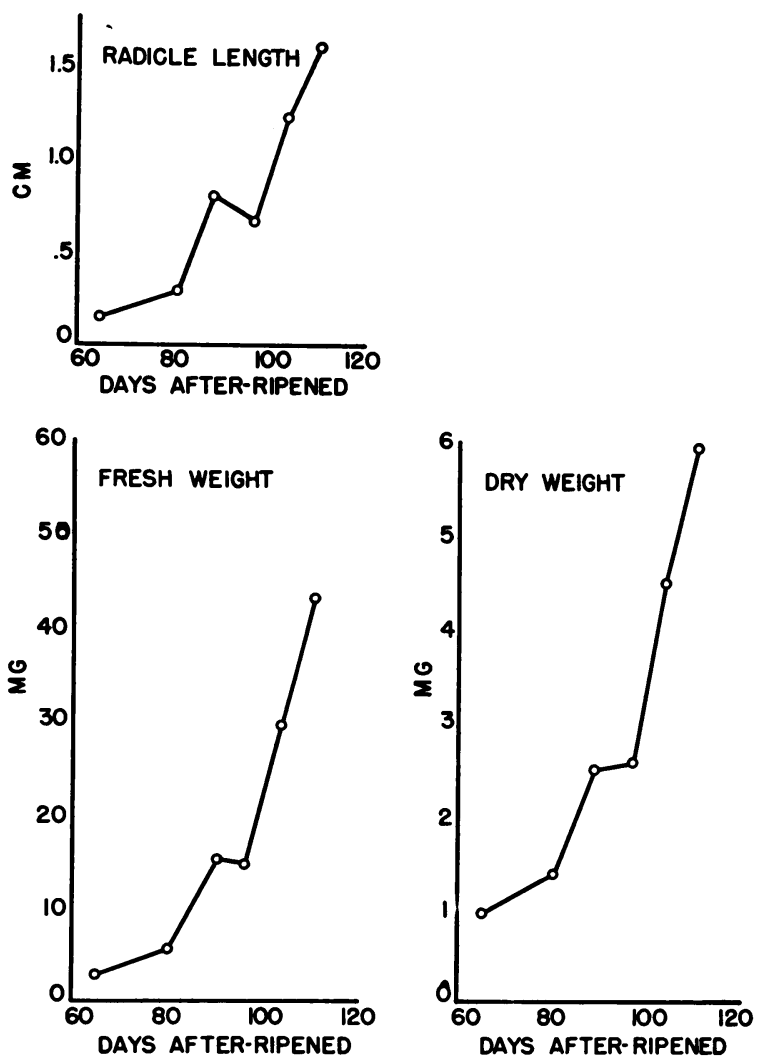

Fig. 14. The effect of length of after-ripening on initial size of Lovell peach embryos (without cotyledons) - experiment 2 .

periment were taken at the same time from different lots that were being held at $36^{\circ} \mathrm{F}$ for different periods. Seeds after-ripened 100 days had most radicles emerging; and those after-ripened longer in all cases had radicles emerging. Radicles of embryos after-ripened 148 days were water-soaked and slightly darker, and appeared to be easily injured. Since maximum growth of seedlings was desired, and because of greater ease in handling the embryo, an after-ripening time of approximately 130 days was maintained for subsequent experiments.

In measuring the initial embryo size in this experiment, a period of delayed radicle elongation was noted between seeds stratified 100 and 115 days. This same phenomenon was observed in a second experiment carried 
out later in the same manner on another lot of seeds. Results of the second experiment were more pronounced and are shown in figure 14. Such an occurrence might mark the separation of two physiological phenomena, the completion of seed after-ripening and the beginning of germination.

These seeds illustrate differences in after-ripening requirements found in

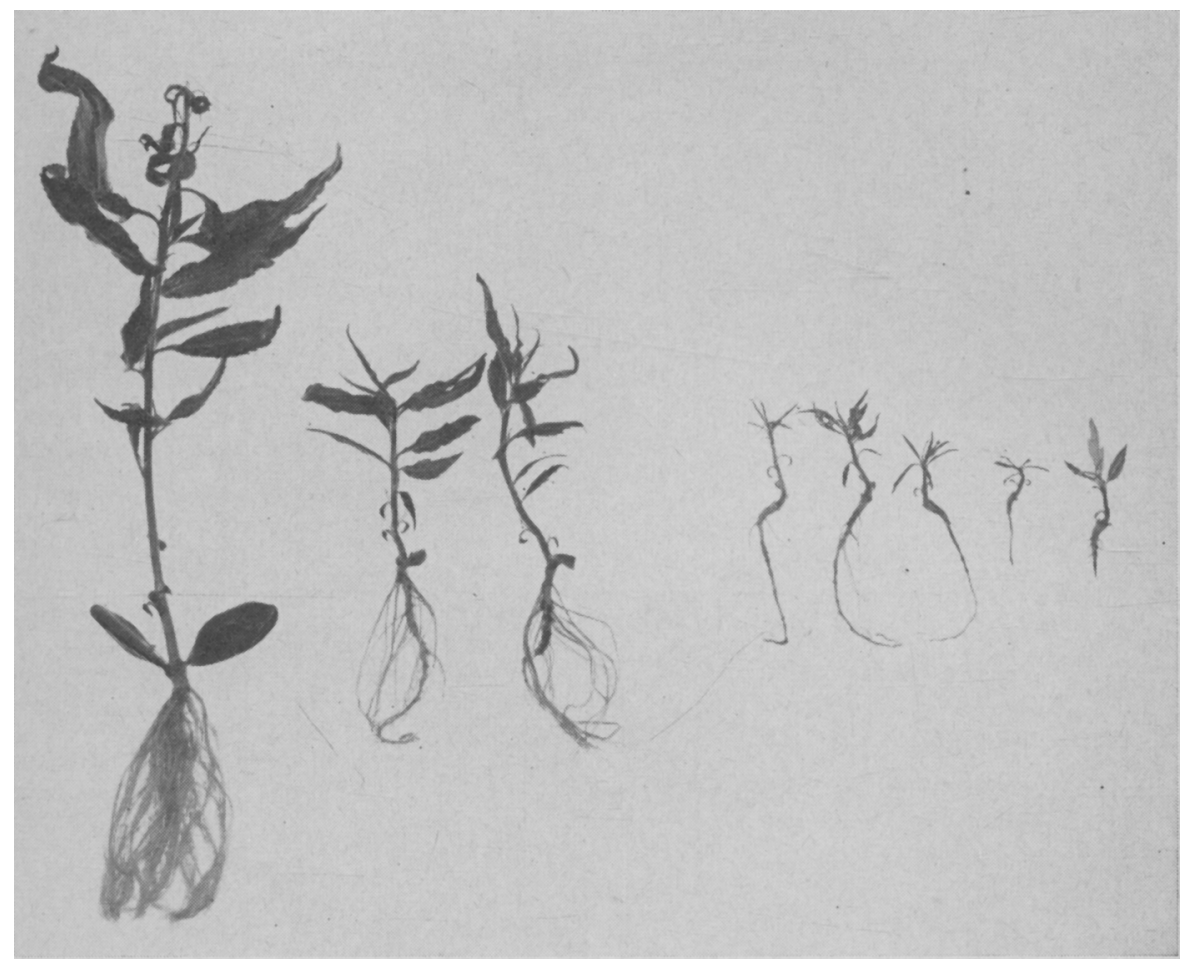

Fig. 15. The effect of cotyledons on the growth of Lovell peach seedlings. Normal seedling on the left was grown on a medium containing only inorganic salts; plants in middle group, with approximately 1/16 of the cotyledons retained, were small but essentially normal; and the group on the right, with both cotyledons removed, had ceased growth. The latter two groups were grown on media to which 4 per cent sucrose was added. Age of all seedlings was 21 days.

different lots. In the latter experiment (as compared with the first) radicles began to emerge at 65 days rather than 81 , the period of delayed radicle elongation began 10 days earlier, and subsequent elongation of the radicle was more vigorous. Such differences suggest that use of an arbitrary time of 130 days may not be satisfactory. Use of such a reference point as the delay in radicle elongation would be desirable to determine the time when cultures should be made, making greater uniformity of the initial embryo possible. In this regard, more extensive experimental data are required. 


\section{Small Amounts of Attached Cotyledon}

Failure of ecotyledonized embryos to maintain growth could be overcome by very small amounts of cotyledons. Figure 15 shows a comparison of ecotyledonized seedlings with seedlings from $1 / 16$ embryos and from whole embryos. Normal seedlings from $1 / 32$ embryos were grown, although smaller than those of $1 / 16$ embryos. Three out of fourteen seedlings showed evidence

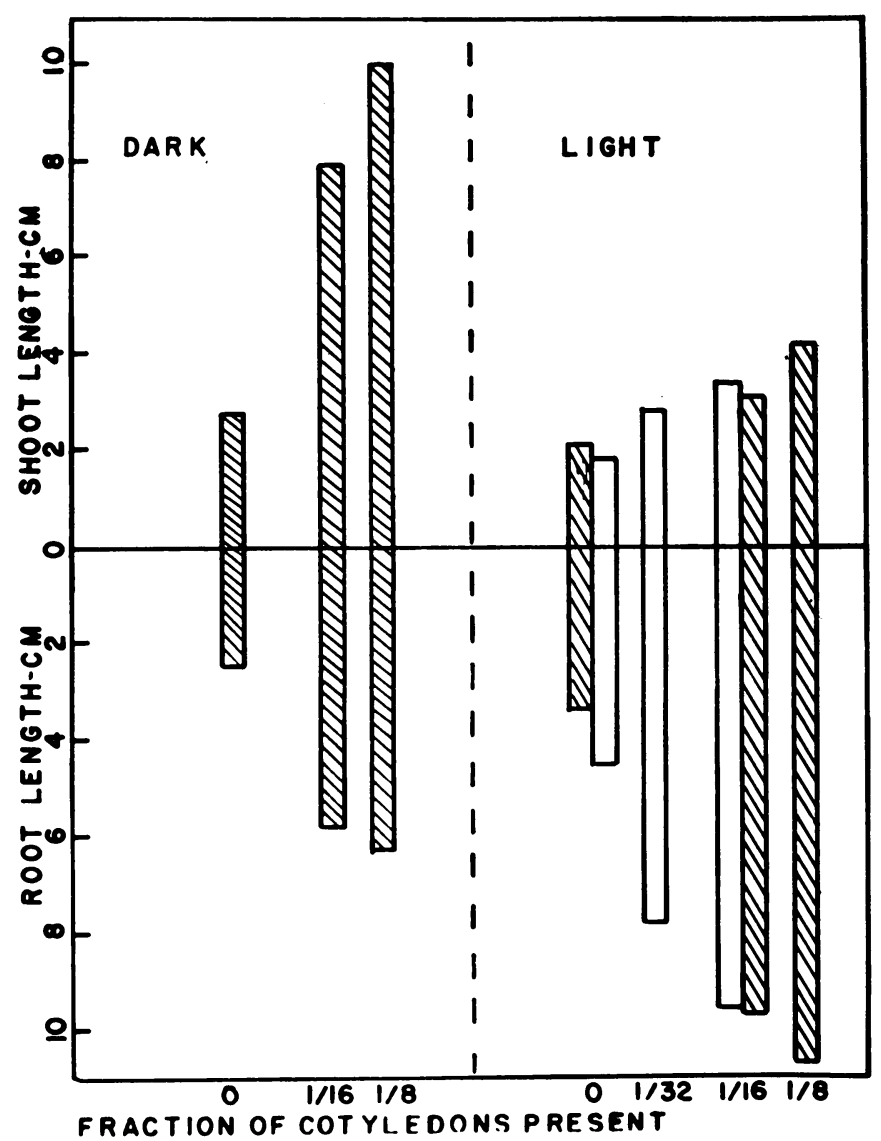

Fig. 16. Shoot and root lengths of seedlings from embryos with different amounts of cotyledons present, grown on a medium containing inorganic salts and 4 per cent sucrose. Differences in shading refer to two different experiments.

of root-tip blackening on some of the laterals near the base. Average initial weight of $1 / 32$ embryos was 9.7 milligrams, or 2.7 per cent of the weight of whole embryos, as compared to 5.2 milligrams, or 1.5 per cent, for the ecotyledonized embryos. The difference of 1.2 per cent indicates the small amount of cotyledons required to produce normal growth.

Final root and shoot lengths of seedlings with varying amounts of cotyledons are shown in figure 16. In the light, roots were longer and had a 
lesser number of laterals than comparable seedlings in the dark. Root elongation of the ecotyledonized seedlings ceased by the fifteenth day and developed blackened tips, but when any cotyledon was present continued to grow

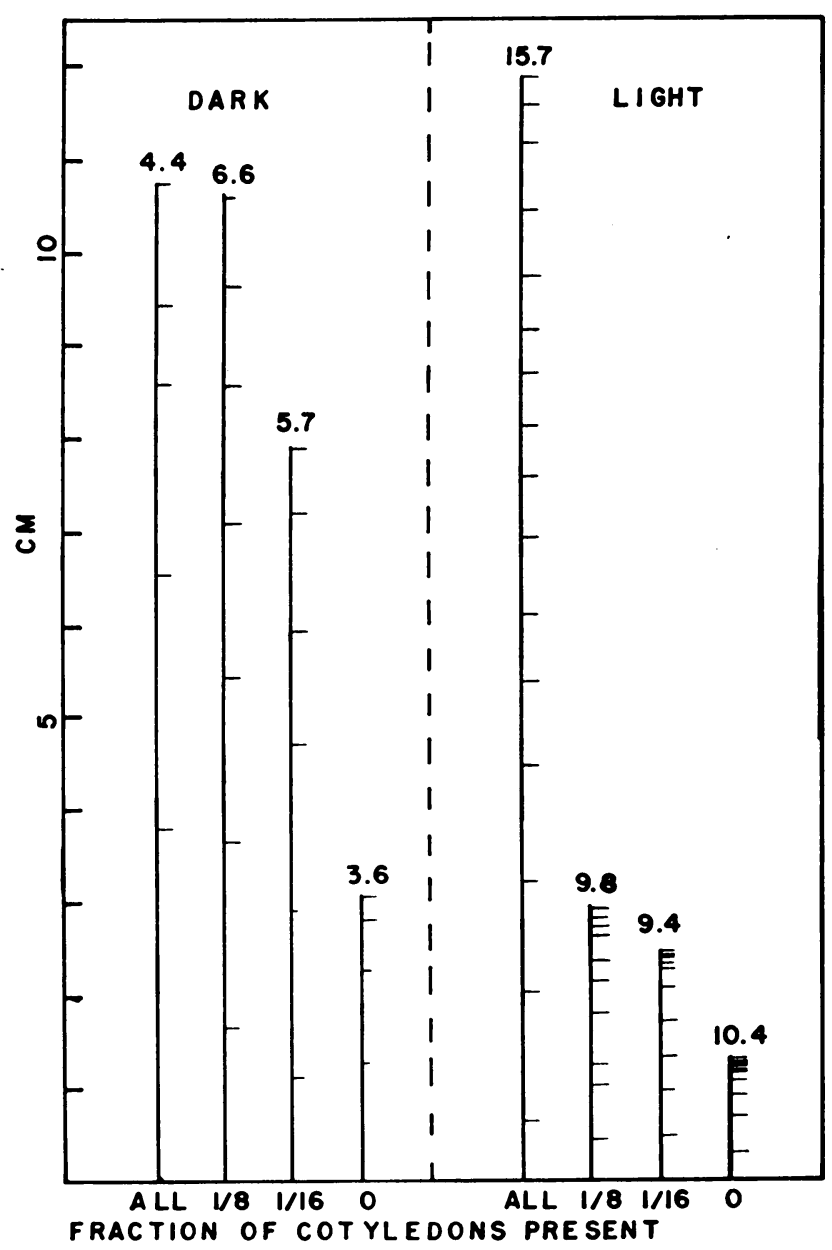

Fig. 17. The average height of shoots of seedlings from embryos with different fractions of cotyledons attached. The position of the node is represented by the horizontal lines; average number of internodes is given above each line. Seedlings were grown 23 days on agar media containing inorganic salts and 4 per cent sucrose. The small size of the seedling from a whole embryo grown in the dark was due to "tip dieback."

normally. In the dark, roots ceased to elongate on all cultures by the tenth day and developed blackened tips even with $1 / 8$ of the cotyledons present.

The shoots, on the other hand, showed greater elongation in the dark than in the light. This reduced shoot elongation in the light was due to inhibition in internode elongation, particularly at the apex, giving rise to a distinctly rosettelike seedling (fig. 17). Inhibition increased with a decrease in the 


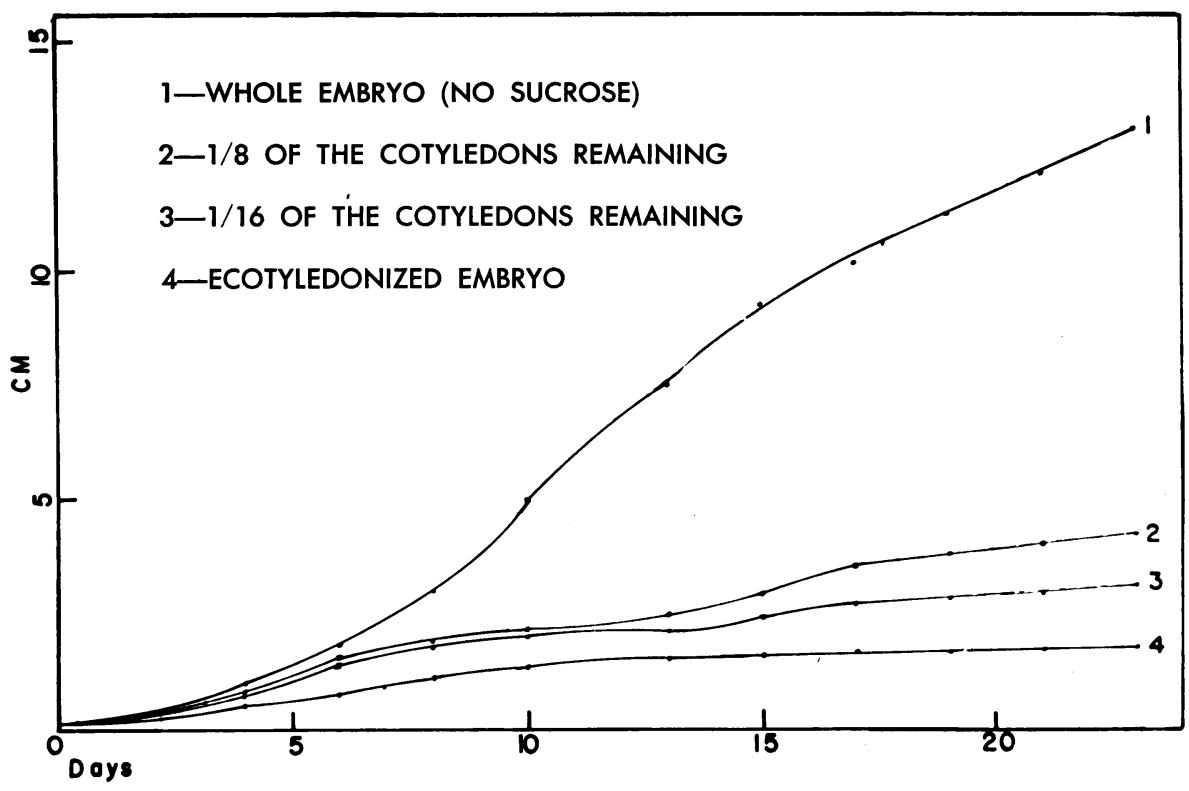

Fig. 18. The daily increase in shoot elongation of Lovell peach seedlings from embryos with different fractions of cotyledons present, grown in light on media containing inorganic salts and 4 per cent sucrose.

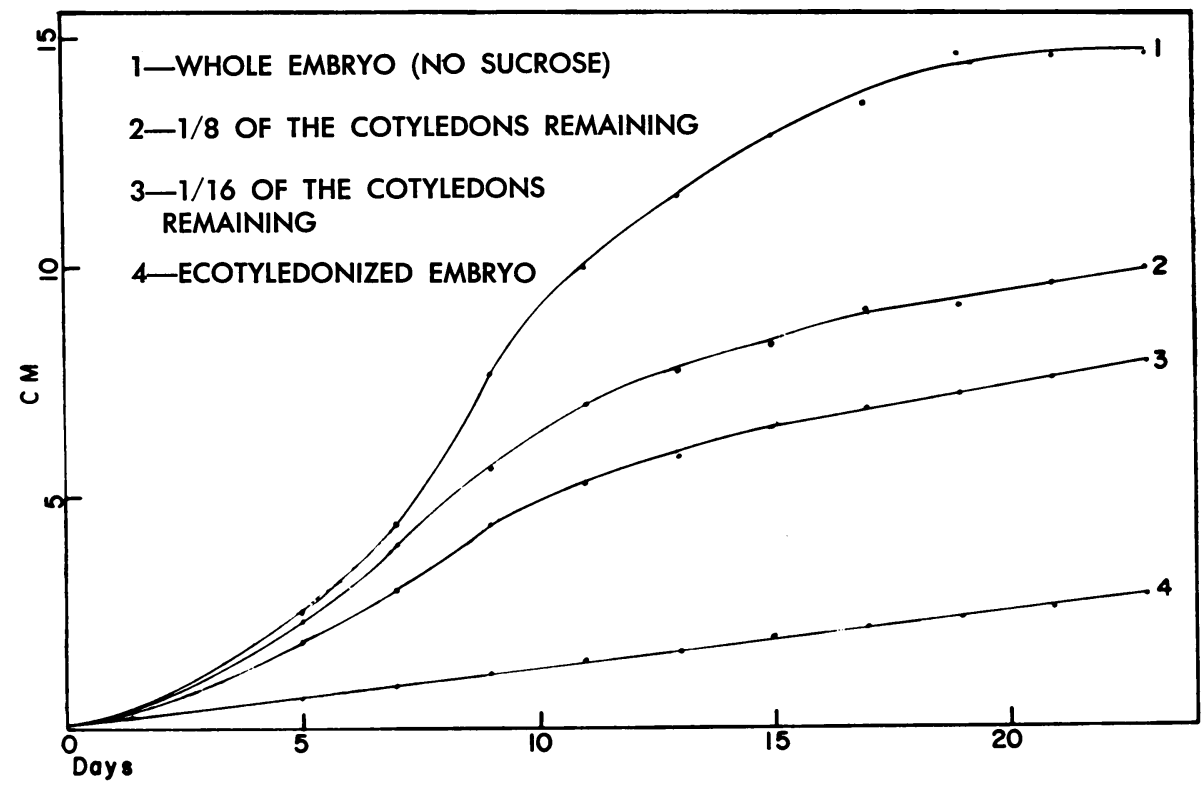

Fig. 19. The daily increase in shoot elongation of Lovell peach seedlings from embryos with different amounts of cotyledons present, grown in the dark on a medium containing inorganic salts and 4 per cent sucrose. 
amount of cotyledons present. Seedlings in the dark were etiolated; difference in size of seedlings with different amounts of cotyledons attached was due to the number of internodes with no evidence of internode inhibition. The small size of the shoot of the whole-embryo seedling in the dark "was due to development of "tip dieback" similar to that described by Gilmore (1950).

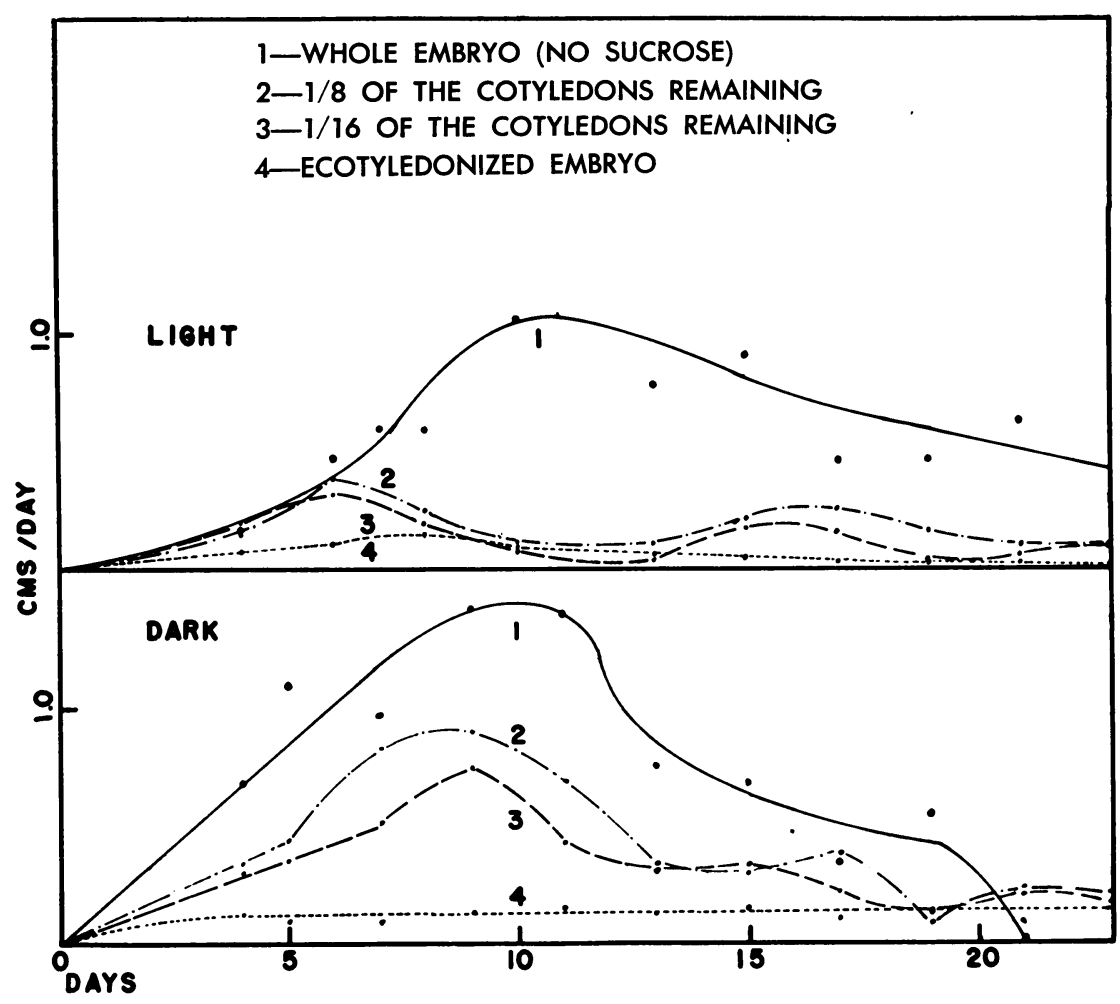

Fig. 20. The rate of growth of Lovell peach seedlings from embryos with different fractions of cotyledons present, grown on a medium containing inorganic salts and 4 per cent sucrose.

The changes in shoot growth throughout the culture period are shown in figures 18 to 20. Differences in growth are again apparent. In the light the rate of growth for ecotyledonized seedlings increased until about the eighth day and then gradually declined to zero; in the dark, on the other hand, growth continued at a uniform rate from the beginning to the end of the culture period. In other seedlings a stimulus in proportion to the amount of cotyledons present was exerted on the rate of shoot elongation. In the dark the maximum growth rate was reached at about the same time, regardless of the amount of cotyledons, followed by a decline to a uniform growth rate. In the light a second stimulus to the rate of growth, also in proportion to the amount of cotyledons, was noted. 


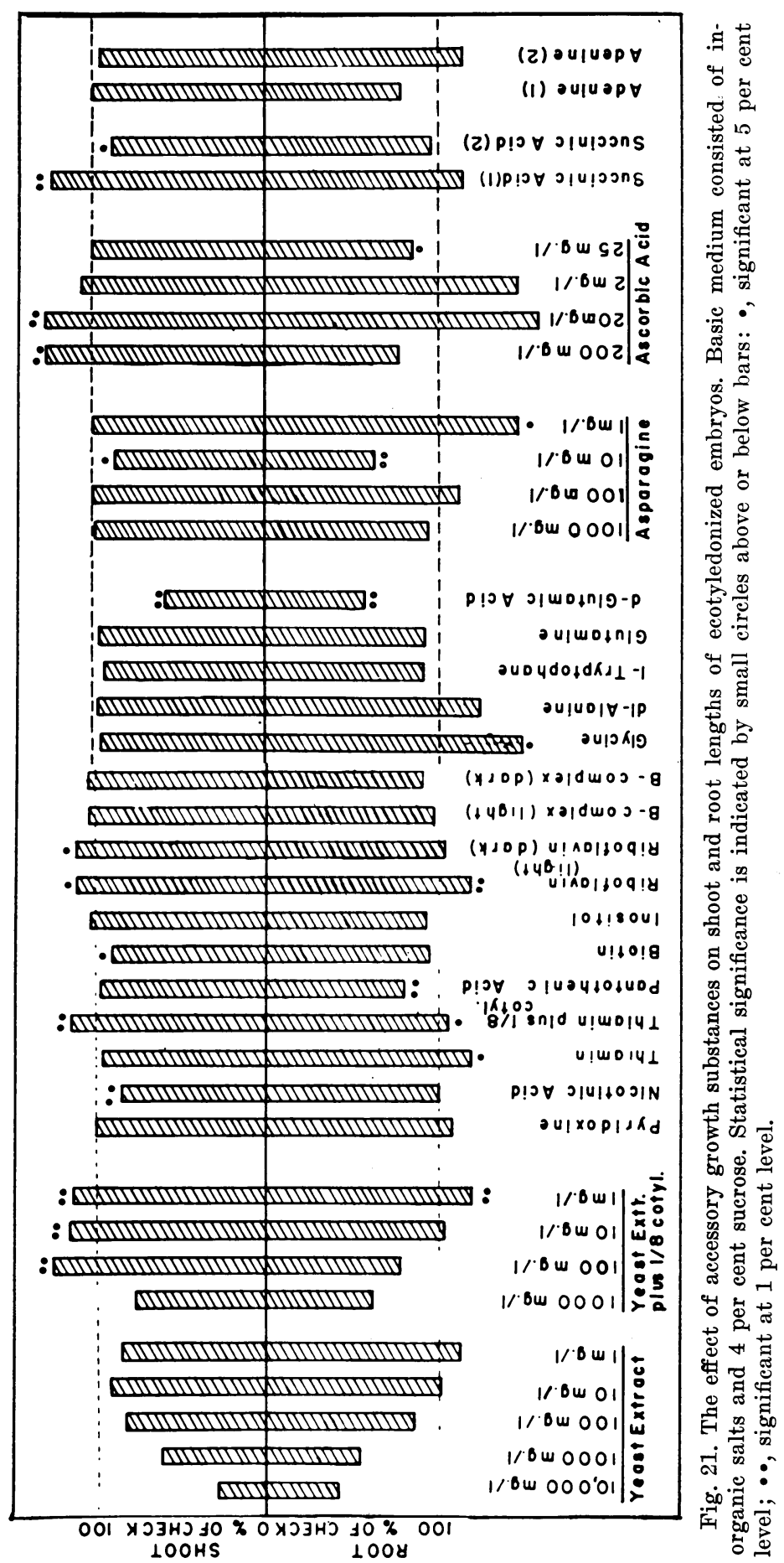




\section{Cotyledon Diffusate}

Since it seemed apparent that small amounts of the cotyledons carried out particular functions or provided factors necessary for continued growth of the seedling, an attempt was made to diffuse possible critical substances from the cotyledon through the agar to the embryo. A cotyledon cut through its lower portion was placed next to the embryo in a series of cultures. Widespread contaminations occurred so that only nine cultures resulted, all of which showed marked inhibition.

Although a specific inhibitor might be involved, possibly under such conditions substances not normally concerned in metabolism are given off and mask any growth-promoting substances present. Toxicity of tissue juices for the living cells of that tissue when applied externally has been shown to occur (Prat, 1927).

\section{Accessory Substances}

The effect of various accessory substances added to the medium containing modified Hoagland's solution and 4 per cent sucrose on growth of ecotyledonized seedlings was investigated. For most of these cultures the seeds used had been after-ripened for 130 days. Cultural conditions were the same as described previously. Thirty cultures were prepared for each treatment and divided into two sets of twelve, leaving six extra cultures for replacements.

Solutions were prepared by mixing agar, inorganic salts, and sucrose with three fourths of the required amount of water. Fifteen milliliters of this solution were added to each test tube. The material to be tested was made up in a stock solution, the amount required for each test tube made up in 5 milliliters. Concentrations used were generally selected arbitrarily from that amount which had been reported to give response in other types of cultures. Five milliliters of the stock solution were then added to each test tube, the tubes shaken to mix the solutions, and the cultures autoclaved for 25 minutes at $250^{\circ} \mathrm{C}$. When a material was used that was affected by autoclaving, the stock solution was sterilized by filtering ${ }^{b}$ and added aseptically to the test tubes after autoclaving. These compounds included thiamin, pantothenic acid, ascorbic acid, and indoleacetic acid. At the end of the experiments, length measurements and fresh- and dry-weight determinations were made. Length measurements were analyzed statistically by the use of the $t$ test for differences between group means (Snedecor, 1948).

Yeast Extract. ${ }^{7}$ Yeast extract was used in a series of concentrations beginning with $10,000 \mathrm{mg}$ per liter, with dilutions down to $1 \mathrm{mg}$ per liter (fig. 21).Two parallel series were used, one of ecotyledonized embryos, the other of embryos with $1 / 8$ of the cotyledons present.

Shoot length of the ecotyledonized embryos was inhibited at all concentrations used. In contrast, shoot length of seedlings with part of the cotyledons still attached was significantly increased at the concentrations of 100 , 10 , and $1 \mathrm{mg}$ per liter.

At $1 \mathrm{mg}$ per liter, length of the root was increased over the check in

${ }^{6}$ Corning fritted disk filter No. 33990.

${ }^{7}$ Bacto yeast extract. Difeo. Detroit, Michigan. 
both series, although only when part of the cotyledons was attached did the increase become statistically significant. Progressive inhibition occurred with an increase in yeast-extract concentration. Lower concentrations than those used here might give greater increases in root length.

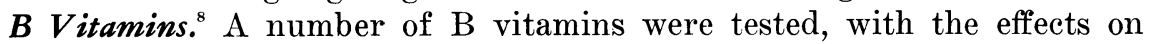
shoot and root growth shown in figure 21. The response of the seedlings to thiamin at $0.2 \mathrm{mg}$ per liter was similar to the response to yeast extract. In the presence of $1 / 8$ of the cotyledons, shoot lengths were significantly increased. On the other hand significant increase in root length occurred whether or not part of the cotyledons was present.

Riboflavin at $0.5 \mathrm{mg}$ per liter produced increases in shoot length in both light and dark and significant increase in root length in the light. Fresh and dry weights were also increased. No increase in either shoot or root growth was produced by adding the following to the medium: pyridoxine (0.5 mg per liter), pantothenic acid ( $0.5 \mathrm{mg}$ per liter), biotin (3 gamma per liter), inositol (0.5 mg per liter), nicotinic acid (1.0 mg per liter), or the combination of all the $B$ vitamins except biotin. Nicotinic acid and pantothenic acid inhibited shoot length, and pantothenic acid inhibited root length at the concentraton employed.

Nitrogen Compounds. " Casein hydrolysate ("vitamin free") to which was added $l$-cystine and $l$-tryptophane at the rate of $6.67 \mathrm{mg}$ per $100 \mathrm{mg}$ of casein hydrolysate was tested at concentrations ranging from $1,000 \mathrm{mg}$ per liter to $31.25 \mathrm{mg}$ per liter. Inhibition of shoot and root lengths occurred at each concentration used. Possibly the effect was one of concentration, since those used were rather high, and lower concentrations might have given definite responses.

Glycine at $3 \mathrm{mg}$ per liter and asparagine at $1 \mathrm{mg}$ per liter gave a slight promotion of the root. Asparagine at $10 \mathrm{mg}$ per liter and $d$-glutamic acid at $3 \mathrm{mg}$ per liter were decidedly inhibitory. $d l$-Alanine and $l$-tryptophane at $10 \mathrm{mg}$ per liter, asparagine at 1,000 and $100 \mathrm{mg}$ per liter, and glutamine at $3 \mathrm{mg}$ per liter had no effect. These results are shown in figure 21.

1-Ascorbic Acid, Succinic Acid, and Adenine. ${ }^{10}$ Conflicting results were achieved with the use of $l$-ascorbic acid (fig. 21). In one experiment it gave highly significant increases to shoot length at 200, 20, and $2 \mathrm{mg}$ per liter, and small though not statistically significant increases to root length at 20 and $2 \mathrm{mg}$ per liter. A later experiment produced no increase in growth

\footnotetext{
${ }^{8}$ Sources of the $B$ vitamins used were as follows:

Thiamin (thiamin hydrochloride) and pyridoxine (pyridoxine hydrochloride), Merck, Rahway, New Jersey.

Riboflavin, inositol, and nicotinic acid, Eastman Kodak, Rochester, New York.

Pantothenic acid (calcium pantothenate), NOPCO Chemical Company, Harrison, New York.

Biotin, General Biochemicals, Inc., Chagrin Falls, Ohio.

${ }^{9}$ Sources of the nitrogen compounds used were as follows:

Casein hydrolysate ("vitamin-free") and glutamine, General Biochemicals, Inc., Chagrin Falls, Ohio.

Glycine, $d l$-Alanine, and $l$-tryptophane, Eastman Kodak, Rochester, New York.

Asparagine (Bacto-asparagine) Difeo, Detroit, Michigan.

d-Glutamic acid, Braun-Knecht-Heimann Co., San Francisco, California.

${ }^{10} l$-Ascorbic acid, succinic acid, and adenine (adenine sulfate) were obtained from Eastman Kodak, Rochester, New York.
} 
at $25 \mathrm{mg}$ per liter. The seeds of the second experiment were those of the second lot, referred to earlier (fig. 14) as having a shorter after-ripening requirement than those of the first lot.

Succinic acid also gave conflicting results (fig. 21). In one experiment it gave an increase in growth by all four measurements, and leaves were noticeably greener than those of other plants of the series. The $\mathrm{pH}$ of the medium had not been adjusted, however, and at the conclusion of the experiment was 4.6 in comparison to 5.5 for the check. A second experiment produced no benefit from adding the succinic acid. The $\mathrm{pH}$ of the latter was adjusted to about 5.8 during preparation. The results suggest that the stimulating factor may have been the $\mathrm{pH}$ rather than succinic acid. $\mathrm{pH}$ may also have been a factor in the ascorbic acid experiment and may account for the differences in results reported there.

Adenine (fig. 21) was added at a concentration of $0.3 \mathrm{mg}$ per liter in two different experiments (fig. 21). Growth was not significantly different from the check in either case.

Indoleacetic Acid. The effect of indoleacetic acid (IAA) was studied in two experiments, one with a series of dilutions starting at $100 \mathrm{mg}$ per liter down to $0.001 \mathrm{mg}$ per liter, the other starting at $1 \mathrm{mg}$ per liter down to 0.00001 per liter. One half of the plants were harvested at 3 weeks in each treatment, the other at 4 weeks. Because of lack of space during the time the latter experiment was being conducted, these particular cultures were not placed directly under the lights but were placed some distance away. The light intensity for the second set was probably about one tenth that of the first.

Morphological response to IAA varied with concentration and differed slightly between the two experiments. In the first at $100 \mathrm{mg}$ per liter, complete inhibition occurred within 5 days, and callus developed on the agar surface. At $10 \mathrm{mg}$ per liter root inhibition occurred, and callus developed but to a lesser degree than at $100 \mathrm{mg}$ per liter. Some plumule growth took place. At $1 \mathrm{mg}$ per liter marked swelling of the radicle occurred producing a nearly bulbous structure, eventually rupturing, exposing masses of whitish, easily separated cells. Adventitious roots arose from within the rupture. At $0.1 \mathrm{mg}$ per liter radicles had greatly increased radial diameter, but with no rupturing. Lateral roots were present, however, and slight elongation occurred. At $0.001 \mathrm{mg}$ per liter growth was similar to that of the checks.

Quantitatively, these changes are shown in figure 22 as general inhibition of shoot and root elongation. Between the third and the fourth weeks a consistent increase in shoot and root elongation took place in the check and at all concentrations less than $1 \mathrm{mg}$ per liter. Weight measurements show a different picture. At 3 weeks the weight, both fresh and dry, of the seedlings growing in IAA solution was considerably less than that of the checks. At 4 weeks, their relative positions reversed, the check being not only lower in weight than any treatment but also lower in weight than the check of the previous week. The sharp maximum in dry weight at $0.1 \mathrm{mg}$ per liter appears to be correlated to the degree of swelling that took place.

The second experiment did not produce the abnormalities of the first. Seedlings in the $1 \mathrm{mg}$ per liter solutions produced radicles that were slightly 
discolored and slightly swollen. Lateral roots became evident at $0.1 \mathrm{mg}$ per liter, and as concentrations were decreased root growth became more normal except for inhibition in length (fig. 23). Shoot growth of all the treatments differed little in appearance from the checks. However, in contrast to experiments under the higher light intensity, shoots were longer with an etiolated appearance, although chlorophyll developed. Length at
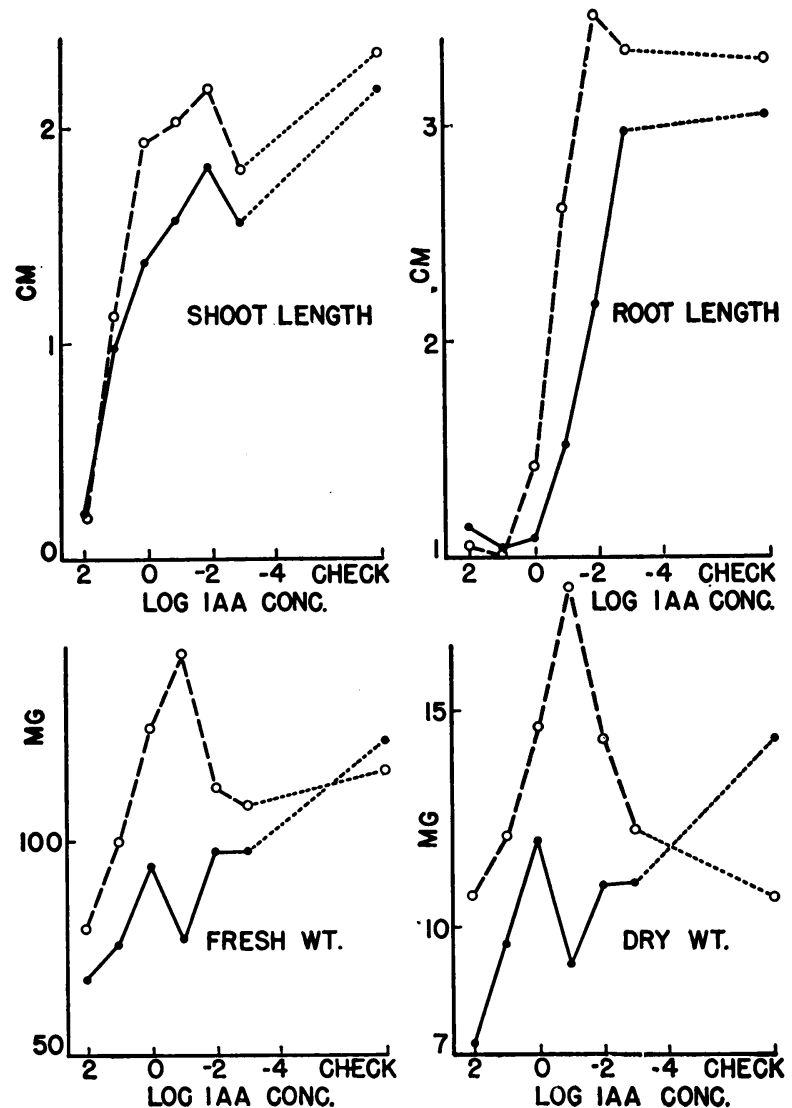

Fig. 22. The effect of indoleacetic acid on growth of ecotyledonized seedlings. The basic medium consisted of inorganic salts and 4 per cent sucrose-experiment 1 . Solid line, growth at 3 weeks; broken line, growth at 4 weeks.

3 weeks on any treatment differed little from the check. However, at 4 weeks, beginning at a concentration of $0.001 \mathrm{mg}$ of IAA per liter, an increase in shoot elongation took place with a decrease in IAA concentration. This trend was reflected in both the fresh and the dry weights, suggesting that a real increase in volume of the shoot occurred. Weight of the check again decreased over that of the previous week, as in the previous experiment. On the other hand, in the plants treated with IAA at the three lowest concentrations, weight increased between the third and fourth weeks. This suggests an actual participation of IAA in metabolism. 


\section{DISCUSSION}

This investigation was started on the premise that a mature germinable embryo with its cotyledons reduced might be analogous to an embryo excised from the fruit at a young stage in development. Growth produced after cotyledon reduction has many features in common with that described for excised immature peach embryos (Tukey, 1938).
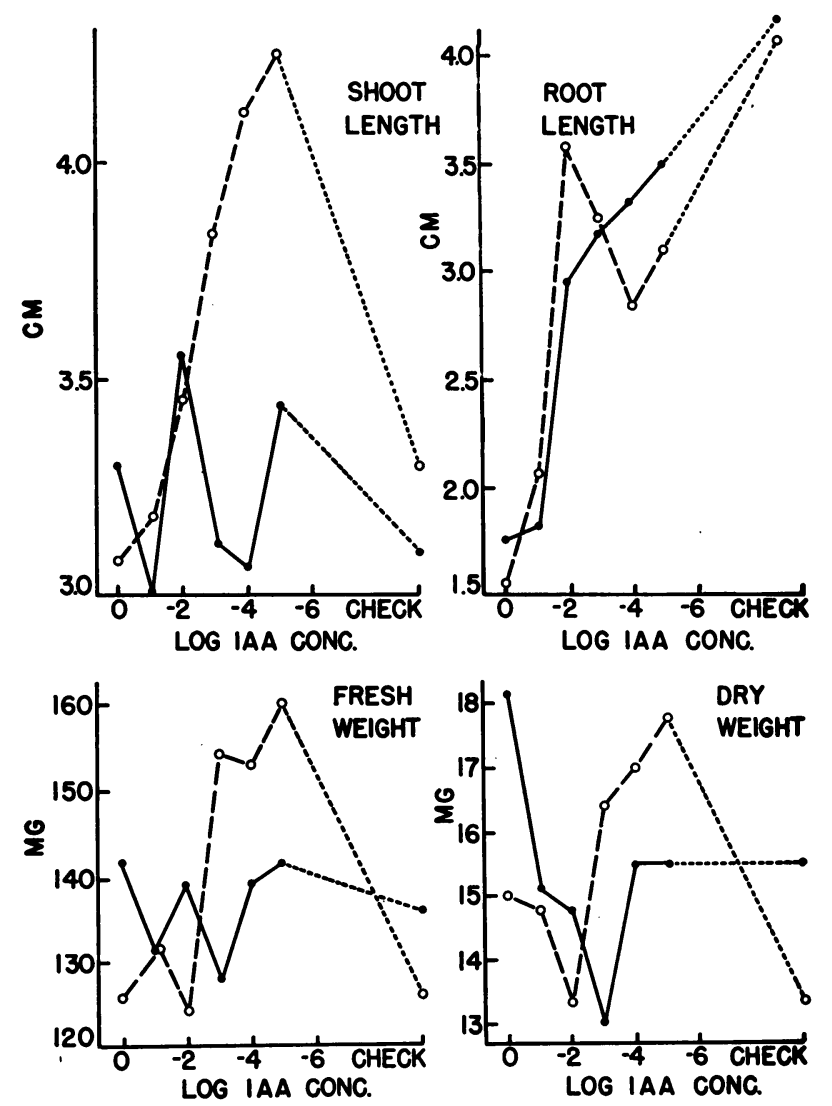

Fig. 23. Effect of indoleacetic acid on growth of ecotyledonized seedlings. Basic medium consisted of inorganic salts and 4 per cent sucrose-experiment 2. Solid line, growth at 3 weeks; broken line, growth at 4 weeks.

\section{Over-All Effects of Cotyledon Reduction}

Over-all growth of peach seedlings, the number and length of internodes, and the total root system were progressively reduced as cotyledon reduction was increased from 0 to nearly 90 per cent. The limiting factor was probably the total reserve substances. When still greater amounts of the cotyledons were removed, the character of the growth changed, and other materials apparently became limiting in addition to "total reserve." Root elongation was curtailed, and shoot growth was limited by a failure of the internodes 
at the shoot apex to elongate. If cotyledons were completely removed, germination did not take place.

\section{Ecotyledonized Embryos}

Supplying sucrose externally to the ecotyledonized embryos made germination possible, although growth was only temporary. The seedlings produced were unlike those from embryos with the cotyledons attached. For instance, elongation of internodes, after the first two or three, was inhibited. Leaf development was abnormal, resulting in a cluster of embryonic leaves and stipules at the shoot apex, although in some cases leaves did unfold and a characteristic rosette was produced. Root elongation continued only briefly, and blackened tips developed. The presence of a very small amount of the cotyledons overcame these characteristics and made possible normal growth.

Growth of these seedlings is similar to growth of seedlings of immature embryos of Elberta peach, as described by Tukey (1938). Growth of the latter was characterized by inhibition of internode elongation, which became more pronounced with younger embryos. Embryos from some of the earliest stages failed to produce normal leaves, the epicotyl being terminated by a rosette of stipulelike appendages. Root elongation was restricted, and the photographs accompanying the descriptions show discolorations at the root tip. Such discolorations at the root tip of seedlings from immature embryos have also been observed by the author in subsequent investigations. Use of ecotyledonized embryos to study germination requirements of immature embryos seems to be justified.

Dwarfing and a rosettelike appearance brought about by a shortening of the internodes is one of the characteristics of seedlings from non-afterripened embryos. In this investigation removal of the cotyledons induced similar growth characteristics in seedlings from embryos that were previously after-ripened. Flemion and Waterbury (1945) could not bring about the dwarfing characteristics of non-after-ripened embryos by reduction of the cotyledons. In their account the smallest amount of cotyledons mentioned was $1 / 3$ of one cotyledon, which produced small but normal plants. Complete removal of the cotyledons resulted in death of the embryo. No sugars were applied, and sterile techniques were not used. The minimum size of embryo which they were apparently able to germinate was larger than that at which dwarfish characteristics appeared here. The similarity does not necessarily mean that the same factors are involved in the two phenomena.

\section{Specific Effects of Cotyledon Reduction}

In peach seedlings growth of the shoot and root differed in its response to different conditions. Thus the response of the shoot to change in sucrose concentration was related to the amount of light, whereas the response of the root was not. In the absence of light, internode inhibition was overcome with growth continuing steadily for at least 21 days while in the presence of light, growth ceased after about 10 days. In darkness, however, root elongation was inhibited, the characteristic tip blackening not being overcome by the cotyledons in the same manner as in light. Again, the response to both yeast extract and thiamin depended on the presence 
of a small amount of the cotyledons, whereas that of the root did not. These facts seem to indicate that growth of the shoot and the root are dependent upon different factors of growth.

The characteristic blackening of the root tips indicates a disruption in the meristematic regions. Certain vitamin deficiencies produce such a breakdown ; for instance, Addicott (1939) has shown that thiamin deficiency has such an effect. In this investigation, thiamin did not overcome this blackening although it did give a slight stimulation to elongation.

Blackening of root tips under certain circumstances has also been reported by Street and Lowe (1950) in their investigations on the carbohydrate nutrition of excised tomato roots. $\mathrm{pH}$ was a critical factor in sucrose absorption, an optimum occurring about 4.8. Values over 5.0 resulted in an inhibition of growth accompanied by a darkening of the root tip. In investigations reported here, $\mathrm{pH}$ was around 5.5 except for a few experiments. In one of these, an unadjusted succinic acid solution with a final $\mathrm{pH}$ of 4.6 gave considerable stimulation to growth, whereas a later experiment with succinic acid adjusted to $\mathrm{pH} 5.5$ gave no such stimulation. The probability exists that the $\mathrm{pH}$ rather than the succinic acid gave the stimulus to growth.

\section{Effect on Rate of Growth}

A stimulating effect of the cotyledons was shown particularly on the rate of stem elongation. In the presence of even a very small amount of cotyledon rate of growth was in direct proportion to the amount of cotyledons. Although other factors enter in, the stimulating effect of the cotyledons appeared to involve predominantly the total amount of reserve substances available. The growth rate increased initially at nearly the same rate for all seedlings and then dropped to produce consecutive maxima in order of the amount of dry matter available.

When sucrose is supplied from the external medium other factors may come into play. In the dark, for instance, maximum shoot elongation was reached at about the same time for seedlings with different amounts of cotyledons. In the light, maxima in shoot elongation of the seedlings from the $1 / 8$ and $1 / 16$ embryos also appeared at about the same time, although measurements made at closer intervals might reveal displacement of such maxima. In this case a second stimulation to the growth rate occurred, again in direct proportion to the amount of cotyledon present. Assuming that the first stimulus was due to mobilization of substances from the cotyledon, another source would need to be used to effect a second stimulus. Increased sucrose absorption or the effect of light on the young expanding leaves might supply such material.

\section{Accessory Substances}

Although none of the accessory substances tested was able to replace the cotyledons and bring about continued growth of ecotyledonized peach embryos, possibly under different conditions, different concentrations, or different combinations success might be achieved. As it was, a number of materials increased root and shoot lengths significantly, indicating a possible participation in metabolism. None of these increases was great, and none approached that brought about by even the smallest amount of cotyledon. 
There is some evidence that auxin relationships are involved in limitation of shoot growth. Shoot elongation with a parallel increase in weight was increased at certain low concentrations of indoleacetic acid (IAA) used under low-light conditions. Whether this indicates that the limiting factor in shoot elongation is auxin or whether it is part of the general effects of auxin on all plant tissues must await further investigations. The fact that seedling weight increased in the presence of IAA and decreased in its absence suggests that it contributed to the general metabolism of the seedling. This increase was a reflection of dry weight rather than water content and, under the higher light intensity, appeared to be correlated to the degree of swelling that occurred.

The presence or absence of light had other effects. Inhibition of shoot elongation was overcome by growing the seedling in darkness, growth continuing steadily for at least 21 days. This was not, however, a practical solution. Root growth, at least elongation, was inhibited by darkness, and root-tip darkening was more pronounced and not overcome by the cotyledons. Reduction of light intensity might produce a point at which light inhibition of the shoot and darkness inhibition of the root is at a minimum. The effect of light on growth of ecotyledonized seedlings should be further investigated.

The removal of the cotyledons has been reported to have no effect upon growth of weeping crabapple embryos when grown on a medium containing sucrose, mineral salts, thiamin, pyridoxine, and glycine (Nickell, 1951). Different species may respond differently to the removal of cotyledons.

The general effects of the cotyledons on growth of after-ripened peach embryos seemed to be of two kinds: (1) production of roots, leaves, and stems, and (2) stimulation of growth after the beginning of germination. Very small amounts of the cotyledons could carry out both functions. A carbohydrate, such as sucrose, was shown to be essential, but in addition other unknown factors for growth were apparently required.

\section{ACKNOWLEDGMENTS}

The author wishes to express his appreciation to Dr. C. O. Hesse for suggesting the problem and for guidance during the course of the study. $\mathrm{He}$ also wishes to acknowledge the helpful suggestions and assistance of $\mathrm{Mr}$. A. E. Gilmore and to express appreciation for the many contributions of various members of the Department of Pomology, Davis, while the investigation was being conducted. 
ADDICOTT, F. T.

\section{LITERATURE CITED}

1939. Vitamin $B_{1}$ in relation to meristematic activity of isolated pea roots. Bot. Gaz. $100: 836-43$.

Avery, G. S., JR., J. Berger, and B. Shalucha

1942. Total auxin extraction from wheat. Amer. Jour. Bot. 29:612-16.

BAKER, G. A., and L. D. DAvis

1951. Growth of the cheek diameter of peaches. Amer. Soc. Hort. Sci. Proc. 57:104-10.

BERGER, J., and G. S. Avery, JR.

1944. Isolation of an auxin precursor and an auxin (indoleacetic acid) from maize. Amer. Jour. Bot. 31:199-203.

Blakeslee, A. F., and S. Satina

1944. New hybrids from incompatible crosses in Datura through culture of excised embryos on malt media. Science $99: 331-34$.

BlociszewsKy, T.

1876. Physiologische Untersuchungen über die Keimung und weitere Entwicklung einzemner samentiele bedecktsamiger Pflanzen. Landw. Jahrb. von Nathusius v. Thiel 5:145. (Quoted by Brown and Morris, 1890.)

BONNER, J.

1938. Nicotinic acid and the growth of isolated pea embryos. Plant Physiol. 13:865-68.

Bonner, J., and G. AxTMAN

1937. The growth of plant embryos in vitro. Preliminary experiments on the role of accessary substances. Natl. Acad. Sci. Proc. 23:453-57.

BONNER, J., and H. BONNER

1948. The B vitamins as plant hormones. Vitamins and Hormones $6: 225-75$.

Brink, R. A., D. C. Cooper, and L. E. Ausherman

1944. Hybrid between Hordeum jubatum and Secale cereale reared from an artificially cultivated embryo. Jour. Hered. 35:67-75.

Brown, H. T., and G. H. MorRIS

1890. Researches on the germination of some of the Gramineae. Jour. Chem. Soc. London $57: 458-528$.

COOPER, W. C.

1938. Hormones and root formation. Bot. Gaz. 99:599-614.

Davidson, O. W.

1933. The germination of "non-viable" peach seeds. Amer. Soc. Hort. Sci. Proc. 30: 129-33.

DIETRICH, K.

1924. Über die Kulture von Embryonen ausserhalf der Samen. Flora N. F. 17:379-417.

Flemion, F., and E. WATterbury

1945. Further studies with dwarf seedlings of non-after-ripened peach seeds. Boyce Thompson Inst. Contrib. 13:415-22.

GILMORE, A. E.

1950. A technique for embryo culture of peaches. Hilgardia $20: 147-69$.

HABERLANDT, G.

1877. Die Schutzeinrichtungen in der Entwicklung der Keimpflanze. Eine biologische Studie, Wien (Quoted by Stingl, 1907).

HaLl, C. B.

1948. Culture of Solanum nigrum embryos. Amer. Soc. Hort. Sci. Proc. 52:343-46.

HanNig, E.

1904. Über die Cultur von Cruciferen-Embryonen. Bot. Zeitung 62:45-80.

Hoagland, D. R., and D. I. ARNon

1938. The water-culture method for growing plants without soil. California Agr. Exp. Sta. Cir. 347:1-39. 
Jorgensen, C. A.

1928. The experimental formation of heteroploid plants in the genus Solanum. Jour. Genet. $19: 133-211$.

Kent, N., and R. A. Brink

1947. Growth in vitro of immature Hordeum embryos. Science $106: 547-48$.

KögL, FRitz, and A. J. HAAGEN-Smit

1936. Biotin und Aneurin als Phytohormone. Hoppe-Seylers Ztsehr. f. Physiol. Chem. $243: 215-26$.

LAIBACH, F.

1929. Ectogenesis in plants. Jour. Hered. $20: 201-08$.

LAMMERTS, W. E.

1942. Embryo culture an effective technique for shortening the breeding cycle of deciduous trees and increasing germination of hybrid seed. Amer. Jour. Bot. 29:166-71.

LARUE, C. D.

1936. The growth of plant embryos in culture. Torrey Bot. Club Bul. 63:365-82.

LEE, F. A., and H. B. TUKeY

1942. Chemical changes accompanying growth and development of seed and fruit of the Elberta peach. Bot. Gaz. 104:348-55.

LOFLAND, H. B., JR.

1950. In vitro culture of the cotton embryo. Bot. Gaz. 111:307-11.

Loo, S. W., and F. H. WANG

1943. The culture of young conifer embryos in vitro. Science 98:544.

MERRY, J.

1942. Studies on the embryo of Hordeum sativum II. The growth of the embryo in culture. Torrey Bot. Club Bul. 69:360-72.

NICKELL, L. B.

1951. Embryo culture of weeping erabapples. Amer. Soc. Hort. Sei. Proc. 57:401-05.

Prat, S.

1927. The toxicity of tissue juices for cells of the tissue. Amer. Jour. But. 14:120-25.

RYTz, W., JR.

1939. Beitrag zum Aneurinstoffwechsel bei hoheren Pflanzen. Schweitz. Bot. Gesell. Ber. 48:339-99.

SACHS, J.

1862. Zur Keimunggeschichte der Gräser. Bot. Ztg. 20:148 (Quoted by Stingl, 1907).

SANDERS, M. F., and P. R. BURKHOLDER

1948. Influence of amino acids on growth of Datura embryos in culture. Natl. Acad. Sci. Proc. 34:516-26.

SMITH, P. G.

1944. Embryo culture of a tomato species hybrid. Amer. Soc. Hort. Sci. Proc. 44:413-16.

SNEDECOR, G. W.

1946. Statistical methods. 4th ed. 485 p. Iowa State College Press, Ames, Iowa.

STEWART, W. S.

1939. A plant growth inhibitor and plant growth inhibition. Bot. Gaz. 101:91-108.

Stingl, G.

1907. Experimentelle Studie über die Ernährung von pflanzlichen Embryonen. Flora $97: 308-31$.

STREET, H. E., and J. S. Lowe

1950. The carbohydrate nutrition of tomato roots. II. The mechanism of sucrose absorption by excised roots. Ann. Bot. [London] n. s. 14:307-29.

TukeY, H. B.

1933a. Artificial culture of sweet cherry embryo. Jour. Hered. 24:7-12.

$1933 \mathrm{~b}$. Growth of the peach embryo in relation to growth of fruit and season of ripening. Amer. Soc. Hort. Sci. Proc. $30: 209-18$. 
1934. Artificial culture methods for isolated embryos of deciduous fruits. Amer. Soc. Hort. Sci. Proc. 32:313-22.

1937. Embryo abortion in the peach in relation to chemical composition and season of fruit ripening. Bot. Gaz. 98:586-97.

1938. Growth patterns of plant development from immature embryos in artificial culture. Bot. Gaz. $99: 630-65$.

van Overbeek, J., M. E. Conklin, and A. F. BlakesleE

1942. Cultivation in vitro of small Datura embryos. Amer. Jour. Bot. $29: 472-77$.

vaN Tieghem, $P$.

1873. Recherches physiologiques sur la germination. Ann. Sci. Nat. Bot. 17:205-24. VON HAUSEN, S. S.

1948. On the role of growth substances in higher plants. Physiol. Plantarum 1:85-94. WENT, F. W.

1938. Specific factors other than auxin affecting growth and root formation. Plant Physiol. 13:55-80. 

The journal Hilgardia is published at irregular intervals, in volumes of about 600 pages. The number of issues per volume varies.

Subscriptions are not sold. The periodical is sent as published only to libraries, or to institutions in foreign countries having publications to offer in exchange.

You may obtain a single copy of any issue free, as long as the supply lasts; please request by volume and issue number from:

\section{Publications Office \\ College of Agriculture \\ Berkeley 4, California}

The limit to nonresidents of California is 10 sepatate issues on a single order. A list of the issues still available will be sent on request.

In order that the information in our publications may be more intelligible it is sometimes necessary to use trade names of products or equipment rather than complicated descriptive or chemical identifications. In so doing it is unavoidable in some cases that similar products which are on the market under other trade names may not be cited. No endorsement of named products is intended nor is criticism implied of similar products which are not mentioned. 